\title{
The Valuation of Corporate Liabilities: Theory and Tests*
}

\author{
Jan Ericsson ${ }^{\dagger} \&$ Joel Reneby ${ }^{\ddagger}$ \\ SSE/EFI Working Paper Series in Economics and Finance No. 445
}

First version: February 2001

January 7, 2003

\begin{abstract}
We develop a structural bond pricing approach and implement it on a large panel of US industrial bonds using an efficient maximum likelihood methodology. We evaluate the model's ability to predict yield spread levels and changes out-of-sample. Errors are smaller and distinctly less variable than those found in previous implementations of structural as well as reduced form models. Furthermore, our analysis provide evidence that bond yield spreads incorporate a substantial liquidity component on top of the default spread structural models are designed to capture.
\end{abstract}

${ }^{*}$ We are grateful to Pascal François, Sune Karlsson, Olivier Renault, Sergei Sarkissian, Paolo Sodini and Paul Söderlind as well as seminar participants at the European Finance Association Annual Meetings in Barcelona, 2nd Thiele Conference in Copenhagen, HEC Montreal, McGill University and Stockholm School of Economics for helpful comments. We are indebted to Olivier Katchadourian for invaluable research assistance. Jan Ericsson gratefully acknowledges financial support from $I F M^{2}$.

${ }^{\dagger}$ McGill University, Faculty of Management, 1001 Sherbrooke Street West, Montreal QC, H3A 1G5 Canada. Tel +1 514 398-3186, Fax +1 514 398-3876. E-mail jan.ericsson@mcgill.ca

${ }^{\ddagger}$ Stockholm School of Economics, Department of Finance, Box 6501, S-113 83 Stockholm, Sweden. Tel: +46 8736 9143, fax +468 312327. E-mail: joel.reneby@hhs.se 


\section{Introduction}

When option pricing theory was developed some thirty years ago, it was suggested that the most fruitful applications would be to the valuation of corporate liabilities. ${ }^{1}$ Yet, there have been surprisingly few attempts to confront structural bond pricing models with market prices. Instead, much of the research in the area has shifted its focus to the development of reduced form models, designed to be more tractable empirically. However, in this paper, we show that our structural approach performs well in comparison to past implementations of structural and reduced form models.

The severity of potential losses from defaults has recently increased. ${ }^{2}$ As a result, accurately assessing the value and the risk of corporate debt is a critical task in many applications. Clearly, it is a prerequisite for making lending decisions and setting prices of new issues. A further important use for credit risky bond valuation models is in the field of risk management: a current issue for the banking sector relates to the measurement of credit risk exposures with a view to determining capital requirements. If, in the medium to long run, current standardized capital ratios enforced by regulators are to be replaced by in-house credit risk models, we will require much more solid knowledge about the performance of different default risk valuation models. ${ }^{3}$

Finally, implementable structural models for corporate liabilities should prove valuable for empirical work in corporate finance. A growing theoretical literature analyses the interaction between security prices and agency problems rooted in the joint capital structure and investment decisions of corporations. Important examples include Anderson \& Sundaresan (1996), Fan \& Sundaresan (2000), Leland (1998), Mella-Barral (1999) and MellaBarral \& Perraudin (1997). The body of empirical work in this field is thin at best.

A pre-requisite for any of these applications is that a model can be

\footnotetext{
${ }^{1}$ See for example Black (1985).

${ }^{2}$ The US corporate debt market makes up roughly a fifth of the total US fixed income markets and has overtaken the Treasury debt market as the second largest segment. The credit risk inherent in corporate bonds creates a substantial challenge in addition to dealing with the already complex term structure risk. For 2001, Moody's reports 186 defaults on corporate bonds in US alone, totalling over 106 billion dollars, about triple the figure for the previous year. The default rate on speculative grade debt rose to more than $10 \%$ in 2001 from a bit less than 6\% in 2000. See Moody's Investors Service (2001), Moody's Investors Service (2002).

${ }^{3}$ See Saunders \& Allen (2002) for an overview of competing approaches to credit risk modelling.
} 
validated empirically. This paper addresses the valuation of credit risky bonds in the context of structural models. These are also often referred to as contingent claims models, as they are based on the premise that a firm's securities can be viewed as "contingent claims" on the assets of the firm. As a result, it is possible to consistently value both the firm's equity and liabilities. This explicit link between stock and bond prices can then be exploited together with balance sheet information to draw inference on the term structure of default probabilities. A related line of research follows Jarrow \& Turnbull (1995) in specifying default probabilities as exogenous stochastic processes. ${ }^{4}$ The models are often referred to as reduced form models, as they do not require a theoretical model of the firm's capital structure.

We develop a structural model for the valuation of corporate debt and implement it on a sample of 141 US corporate bonds totalling 5594 dealer quotes. In contrast to many previous papers, we make a clear distinction between the firm's total debt and the particular bond that we wish to value. This has the advantage of combining (i) simple closed form solutions for the value of the firm's securities, which is crucial for our estimation procedure to be tractable with (ii) an accurate model allowing for the salient characteristics of the firm's capital structure as well as the individual bond's contractual features. Moreover, our econometric methodology, based on a maximum likelihood approach developed by Duan (1994), makes more efficient use of the information in time series of stock prices than previously applied methods.

We find that our approach outperforms previous implementations of structural models. When including a bond price in the sample, yield spread errors out-of-sample are comparable to or smaller than those reported in recent studies of reduced form models. We also provide evidence on the model's ability to predict changes in yield spreads. Our model is able to better predict large changes in spreads, in contrast to small changes which we show are more likely to be driven by noise or liquidity. Furthermore, pricing bond portfolios, we show that the greater part of the model errors are diversifiable. Analyzing the errors using a set of bond specific and economy wide variables, we find support for the notion that bond spreads incorporate a substantial liquidity premium on top of the default premium the models are designed to capture. Another interesting result is that our model, although it does not incorporate a stochastic risk free term structure,

\footnotetext{
${ }^{4}$ A non exhaustive list of contributions in this literature would include Duffie \& Singleton (1999), Jarrow et al. (1997), Lando (1998), Lando (1997).
} 
generates correlations between the level and the slope of the risk free term structure in line with those reported in for example Longstaff \& Schwartz (1995) and Duffee (1998).

As already noted, there have been very few empirical tests of structural bond pricing models. The first published test of contingent claims models for the valuation of corporate debt was carried out by Jones et al. (1984). They find that their model systematically overprices bonds by on average almost 9\%. Ogden (1987) finds the same result in a similar study. ${ }^{5}$ Although more recent theoretical models have addressed the weaknesses suspected to be responsible for the failure of earlier studies, these papers are often cited to support the notion that structural models in the wake of Black \& Scholes (1973) are unsuited for practical work as they are unable to generate sufficiently high yield spreads. However, more than forty years ago, Fisher (1959) argued that bond yield spreads consist of compensation not only for credit risk but also for marketability risk. Recent work supports this idea and we will use this as our point of departure. Huang \& Huang (2002) and Delianedis \& Geske (2001) show that the spread on investment grade bond is determined primarily by non-credit risk factors such as liquidity. ${ }^{6}$ Consequently, a structural bond pricing model should be expected to overprice corporate bonds even if it correctly assesses the part of the yield spread driven by default risk.

Anderson \& Sundaresan (2000) estimate a set of structural models on aggregate corporate bond yield indices and find that the correlation between estimated and market BBB rated spreads is approximately $50 \%$ in-sample depending on model specification. We find correlations out-of-sample for individual bond spreads averaging about $60 \%$ for all of our sample and $76 \%$ out-of-sample for speculative grade bonds. Given that their results are based on in-sample estimation at an aggregate level, we view our results as encouraging.

A recent study by Eom et al. (2002) is more directly comparable to our work. They assess the empirical performances of the Merton (1974), Geske (1977), Longstaff \& Schwartz (1995), Leland \& Toft (1996) and Collin-

\footnotetext{
${ }^{5}$ Cossin \& Pirotte (1996) test the Longstaff \& Schwartz (1995) model on very low credit spread (average 3.5 basis points), short term swap data and also get disappointing results. Wei \& Guo (1997) test the Longstaff \& Schwartz (1995) as well as the Merton (1974) model on Eurodollar futures - which also are of high rating and short maturity. Again, the results are discouraging. Lyden \& Saraniti (2000) test the same two models and find that both models overprice bonds. Delianedis \& Geske (1999) find, however, that the Merton and the Geske models can predict rating migrations.

${ }^{6}$ Other papers that discuss this issue include Ericsson \& Renault (2000), Janosi et al. (2001), Yu (2002).
} 
Dufresne \& Goldstein (2001) on a cross-section of individual bonds, and find that the models generate systematically biased price estimates, although not always in the direction found by Jones et al. (1984). The out-of-sample yield spreads predicted by our model are biased in the direction suggested by Huang \& Huang (2002) and Delianedis \& Geske (2001) while the variability of the errors is of a lesser magnitude than that of previous studies. Conditioning on bond prices, our model produces unbiased estimates and has predictive power for changes in the credit spread. The errors of the model are analyzed using a set of bond specific, firm specific and economy wide variables. In particular, we find that our model's errors can be explained by proxies for the liquidity spread in Treasury markets.

Duffee (1999) provides an empirical study of the reduced form approach. However his results are not directly comparable to those in this paper as he gauges the in-sample fit of bond prices rather than out-of-sample predictions. Nevertheless, the errors produced by our models are similar in magnitude. In addition, our model compares favourably to the results of a study of outof-sample performance by Bakshi et al. (2001). Overall, our results lead us to be more optimistic about the prospects of structural modelling of credit risk as a practical tool in finance than most earlier studies have given us reason to feel.

The structure of our paper is as follows. We begin by describing our capital structure and security valuation model. We then describe the econometric methodology and the data sources employed. A small simulation study forms the introduction to the main section where we present the results of various tests, relate them to previous work and analyze the model errors. Finally we provide a concluding discussion.

\section{Theoretical Model}

In this section, we discuss the basic economic setting on which we base our model. ${ }^{7}$ We make the standard assumptions of Black \& Scholes (1973) and Merton (1974) about the economy. Arbitrage opportunities are ruled out and investors are price takers. Furthermore, for at least some large investors, there are no restrictions on short selling stocks or risk free bonds and these can be traded costlessly and continuously in time. ${ }^{8}$ There are no assumptions about the tradeability of corporate bonds.

\footnotetext{
${ }^{7}$ The presentation is a condensed version of Reneby (1998).

${ }^{8}$ See Merton (1990) chapter 14 for a discussion.
} 
The constant risk free interest rate is $r$. Many models incorporate stochastic interest rates. ${ }^{9}$ This is important to the degree that credit risk is correlated with interest rate risk. Although from an economic perspective it appears natural that high interest rates are correlated with harsh business conditions and thereby increased default risk, it is not obvious that this is a first order effect. Unique credit risk might be by far the most important risk factor. Indeed, to quote Fridson et al. (1997), "empirical investigations have not identified interest rates as an important determinant of default rates on high-yield bonds". ${ }^{10}$ The comparative statics of the Longstaff \& Schwartz (1995) model suggest a negative relationship between the level of interest rates and yield spreads and they find empirical support for their result. Duffee (1999) similarly finds a negative but weaker correlation. We will return to this issue in the discussion of our empirical results, examining whether omitted term structure variables can explain yield spread prediction errors.

\subsection{The state variable}

The state variable used in structural models is based on the value of the firm's assets. The prices of the firm's securities depend on the share of the firm value that each security holder is entitled to, when the firm is solvent as when it is in financial distress. In this setting, corporate securities and their derivatives are valued as claims contingent on the underlying asset state variable.

Assets are assumed to generate revenue that is not reinvested. This "free cash flow" is used to service debt or paid out as dividends to shareholders. Throughout, we assume that our state variable has the following dynamics

$$
\left\{\begin{array}{l}
d \omega_{t}=(r+\lambda \sigma-\beta) \omega_{t} d t+\sigma \omega_{t} d W_{t} \\
\omega_{0}=\underline{\omega}
\end{array}\right.
$$

where the generated cash flow is equal to $\beta \cdot \omega_{t}$ with $\beta$ a constant revenue rate. The variable $\omega$ has a natural interpretation as the (after-tax) value of assets in that it is indeed equal to the value of receiving all future cash flow. ${ }^{11}$ The term $(r+\lambda \sigma)$ is the expected return from holding the assets -

\footnotetext{
${ }^{9}$ E.g. Longstaff \& Schwartz (1995), Kim et al. (1993), Saá-Requejo \& Santa-Clara (1997) and Nielsen et al. (1993).

${ }^{10}$ Examples of such studies are Fridson \& Kenney (1994) and Reilly \& Wright (1994).

${ }^{11}$ I.e., the solution to the integral $E^{B}\left[\int_{t}^{T} e^{-r(s-t)} \beta \omega_{s} d s\right]$, where $E^{B}$ respresents the expected value under the risk-adjusted probability measure, is $\omega_{t}$. Observe that we do not assume that assets or corporate bonds are traded; we only need to assume that some corporate security, e.g. equity, is traded. This issue is discussed in detail in Ericsson \& Reneby (1999).
} 
including accumulating the free cash flow $\beta \omega$. The growth rate of assets is $(r+\lambda \sigma-\beta)$. The parameter $\sigma$ is the volatility of the asset value and $\lambda$ can be interpreted as the market price of risk associated with the operations of the firm.

\subsection{The firm's liabilities}

It is important to make a distinction between securities that, in nominal terms, constitute a small part of the firm's debt - such as a bond issue - and securities that appear on an aggregate level - such as equity. In many papers it is assumed, at least indirectly, that total debt is made up of a single bond issue. Consider for example the model of Geske (1977), in which a coupon payment is valued as a compound option on later payments. Bankruptcy occurs when the value of assets is so low that equity holders no longer find it profitable to honour a coupon payment. Although the idea of shareholders taking into account future debt obligations when deciding on debt service is important, modelling individual payments is not tractable. ${ }^{12}$ In practice, there will be a multitude of other payments, in between payments to the holder of the bond you want to value, that might be the cause of bankruptcy. Thus equity cannot be valued as the residual of a single bond issue, but as a residual claim to a cluster of liabilities.

A firm's debt consists of bank loans, bonds, accounts payable, salaries due, accrued taxes etc. Dues to suppliers, employees and the government are substitutes for other forms of debt. Part of the price of a supplied good and part of salary paid can be viewed as corresponding to compensation for the debt that, in substance, it constitutes. The cost of debt consequently includes not only regular interest payments to lenders and coupons to bondholders, but also fractions of most other payments made by a company. Clearly, a comprehensive model of all these payments would not be tractable.

To obtain a simple closed form value for equity, we assume that debt service takes place continuously. Also, since most companies do not have a predetermined life span, a firm is assumed, conditional on no default, to continue its operations indefinitely. Equity is then valued in the spirit of the Black \& Cox (1976) and Leland (1994) models.

However, unlike in those models, we allow the firm to alter the total amount of debt over time. A model that does not account for the possible

\footnotetext{
${ }^{12}$ In Geske's framework each coupon payment leads to an additional compound option and quickly requires solving high-dimensional normal distributions. When there are more than a few payments this becomes difficult to deal with computationally.
} 
increase in total debt, may imply a term structure of default probabilities at odds with reality. Since the expected value of the asset value increases exponentially, the expected debt to equity ratio would tend toward zero at long horizons and the probability of financial distress would be heavily skewed to the early part of the company's life - in effect, to the first couple of years (see Reneby (1998)).

We denote total nominal debt by $N_{t}$. Although the increase in total debt is the result of many small debt issues, we assume that it can be approximated, on an aggregate level, by a continuous growth rate $\alpha$ :

$$
\left\{\begin{array}{c}
d N_{t}=\alpha N_{t} d t \\
N_{0}=\underline{N}
\end{array}\right.
$$

In other words: $\alpha N_{t} d t$ is the extra principal to which the firm must commit itself in a given moment. For future reference, let $d\left(\omega_{t}, t\right) d t$ denote the market value of a loan with principal $\alpha N_{t} d t$. Since all issues are assumed to be floated at a fair price, $d\left(\omega_{t}, t\right) d t$ is also the amount borrowed each instant. $^{13}$

Total debt service at time $t$ is denoted by $C_{t}$ which consequently also increases at rate $\alpha$. Interest payments increase as new debt is contracted and needs to be serviced, and not because the debt service to a given liability increases. Interest payments are tax-deductible and the corporate tax rate is $\tau$.

Assuming that aggregate debt has the simple structure outlined above implies that it will not be affected by the characteristics of the specific debt instrument to be valued. Since equity is valued as the residual of aggregate debt, those characteristics will not affect the valuation formula for equity either. Intuitively, the single debt issue is too small to have a significant effect on the overall debt level. One can thus derive pricing formulae for equity and individual debt instruments separately. This is crucial to combine realistic modelling of debt instruments - allowing for discrete coupons or callability, for example - with retained analytic formulae for equity value.

\subsection{Financial distress}

The firm is assumed to enter financial distress when the value of its assets falls below $L_{t}$ - the reorganization threshold. The time of this event is denoted $\mathcal{T}$. We assume that at this point the value of the assets, net of reorganization costs, is distributed to claimants. We allow for violations

\footnotetext{
${ }^{13}$ The pricing equation for debt is given in appendix.
} 
of the absolute priority rule and thus shareholders can also be expected to acquire a fraction of the assets. Reorganization should be understood to encompass events ranging from write-downs of certain claims or infusion of capital to asset liquidations.

The payoff to claimants in reorganization may be in the form of cash or new securities. We use $\varepsilon$ to denote the fractions of assets paid out to equity holders and $k$ the fractional bankruptcy costs. Hence $L_{\mathcal{T}}-\varepsilon \cdot L_{\mathcal{T}}-k \cdot L_{\mathcal{T}}$ quantifies the payoff to debtholders. These payoffs can be thought of, and even modelled as, the outcome of a strategic game played between equity holders and various debtholders over the reorganizing firm.

We assume that the reorganization threshold is the level of asset value at which shareholders are no longer willing to contribute funds to stave off financial distress. ${ }^{14}$ This choice of $L_{t}$ is the lowest possible which is consistent with limited liability. Hence, the $L_{t}$ is endogenously determined and will depend on firm specific parameters such as riskiness of the assets, the cash flow rate as well as the risk free interest rate. ${ }^{15}$ One obvious but important implication of our assumption of debt growth is that $L_{t}$ will also grow at a rate $\alpha$.

\subsection{Equity}

Equity derives its value from dividends $(D I V)$ and, to a lesser degree, from payoffs in the event of default - i.e. violations of the absolute priority rule. To denote default formally, we use an indicator function. The indicator function $I_{\mathcal{T} \nless s}$ takes on the value of unity if default has not yet occurred at time $s$, and the value of zero if it has. The value of equity is calculated as the discounted expected value, under the risk-adjusted measure $Q^{B}$, of future payoffs:

$$
\mathcal{E}\left(\omega_{t}, t\right) \equiv\left\{\begin{array}{c}
E^{B}\left[\int_{t}^{T} e^{-r(s-t)} D I V\left(\omega_{s}, s\right) I_{\mathcal{T} \nless s} d s\right] \\
+E^{B}\left[e^{-r(\mathcal{T}-t)} \varepsilon_{\mathcal{T}} L_{\mathcal{T}}\right]
\end{array}\right.
$$

No profits or losses are carried forward - cash flows net of taxes and interest payments are distributed to the equity holders. At any given point in time $s$, the following cash flow is available:

$$
\operatorname{DIV}\left(\omega_{s}, s\right)=\beta \omega_{s}-C_{s}+\tau C_{s}+d\left(\omega_{s}, s\right)
$$

\footnotetext{
${ }^{14}$ However, several other choices are possible. E.g. the barrier can be set equal to (a fraction of) the nominal amount or as the outcome of a strategic game. Since aggregate debt is of infinite maturity, the solution to a game will be time-invariant.

${ }^{15} \mathrm{~A}$ closed form solution for the default threshold can be found in the appendix.
} 
i.e., the dividend stream is determined by four components:

- the (after-tax) earnings generated by the firm's operations ${ }^{16}$

- less coupon payments

- plus the tax-savings on coupons

- plus the inflow from debt issues. This is interpreted as borrowing to keep up the payout ratio; if the firm would not borrow, it would have to plow back more earnings - reducing dividends - to uphold a given investment strategy. Thus external funds $(\alpha)$ and free cash flow $(\beta)$ are complementary for this purpose.

A negative dividend corresponds to a situation where equity holders contribute funds to stave off financial distress. This is, of course, done in their own self interest since the value of expected gains in the future exceeds those payments.

Before providing the solution to the integrals in (2), we define two fictive claims, both related to payoffs in default, that will be the building blocks of the equity formula.

Lemma 1 Define $G$ as the value of a claim paying off unity in financial distress.

$$
G\left(\omega_{t}, t\right) \equiv E^{B}\left[e^{-r \mathcal{T}} \cdot 1\right]
$$

Its value is

$$
G\left(\omega_{t}, t\right)=\left(\frac{\omega_{t}}{L_{t}}\right)^{-\theta}
$$

with the constant given by

$$
\left\{\begin{array}{l}
\theta=\frac{\sqrt{\left(\mu^{B}\right)^{2}+2 r}+\mu^{B}}{\sigma} \\
\mu^{B}=\frac{r-\beta-\alpha-0.5 \sigma^{2}}{\sigma}
\end{array}\right.
$$

The result is derived in the appendix.

\footnotetext{
${ }^{16}$ All values in the model are after-tax; thus $\beta \omega$ can be thought of as "EBIT plus taxes": EBI.
} 
Lemma 2 Define $G^{\alpha}$ as the value of a claim paying off $e^{\alpha(\mathcal{T}-t)}$ in financial distress.

$$
G^{\alpha}\left(\omega_{t}, t\right) \equiv E^{B}\left[e^{-r \mathcal{T}} \cdot e^{\alpha(\mathcal{T}-t)}\right]
$$

Its value is

$$
G^{\alpha}\left(\omega_{t}, t\right)=\left(\frac{\omega_{t}}{L_{t}}\right)^{-\theta^{\alpha}}
$$

with the constant given by

$$
\left\{\begin{array}{c}
\theta^{\alpha}=\frac{\sqrt{\left(\mu^{B}\right)^{2}+2(r-\alpha)}+\mu^{B}}{\sigma} \\
\mu^{B}=\frac{r-\beta-\alpha-0.5 \sigma^{2}}{\sigma}
\end{array}\right.
$$

The result is derived in the appendix.

The first claim, $G$, quantifies the risk of default. Its value is related to the probability of default, but adjusted for the time value of money. It will henceforth be referred to as the "dollar-in-default" claim. The second claim, $G^{\alpha}$, pays off a dollar in default which has been compounded at a rate $\alpha$. Consider e.g. a claim to receive the assets in default: the potential payoff is $\omega_{\mathcal{T}}=L_{\mathcal{T}}=L_{t} \cdot e^{\alpha(\mathcal{T}-t)}$ and the value must be $L_{t} \cdot G^{\alpha}$. Finally, note that $0 \leq G \leq 1, G \leq G^{\alpha}$ and that $G^{\alpha}$ can be worth more than one when $\alpha>r$.

With the help of the claims in Lemmas 1 and 2, the solution to equation (2) is rather simple and intuitive. It is given in the following proposition.

Proposition 1 The price of equity is given by

$$
\begin{aligned}
\mathcal{E}\left(\omega_{t}, t\right)= & \omega_{t}-L_{t} \cdot G^{\alpha}\left(\omega_{t}, t\right) \\
& -N_{t} \cdot\left(1-G\left(\omega_{t}, t\right)\right) \\
& +\tau N_{t} \cdot \frac{r}{r-\alpha} \cdot\left(1-G^{\alpha}\left(\omega_{t}, t\right)\right) \\
& +(1-\varepsilon-k) \cdot L_{t} \cdot\left(G^{\alpha}\left(\omega_{t}, t\right)-G\left(\omega_{t}, t\right)\right) \\
& +\varepsilon L_{t} \cdot G^{\alpha}\left(\omega_{t}, t\right)
\end{aligned}
$$

where $G$ and $G^{\alpha}$ are given by Lemmas 1 and 2. The result is derived in the appendix. (This formula only holds provided $r \neq \alpha$; the formula for $r=\alpha$ is found as the limiting case. It does hold for $\beta=0$.)

The interpretations of the terms of the formula are the following:

- The first line is equal to the value of receiving all the firm's earnings conditional on no default. 
- The second line is the cost of servicing current debt holders - intuitively, it is the value of risk free debt $\left(N_{t}\right)$ times a factor reflecting the risk of default.

- The third line corresponds to the value of the tax shield ( $\tau$ is the tax rate). It incorporates the tax shield accruing from debt service to current debtholders as well as the tax shield stemming from debt floated in the future.

- The fourth line is the value, for equity holders, of being able to borrow in the future using the assets as collateral. Since $(1-\varepsilon-k) L_{t}$ is recovered by debtholders in default, it can be interpreted as the current value of that collateral.

- The fifth line, finally, is the value of expected payouts to equity holders in reorganization.

To obtain some additional intuition for the equity formula, consider the following scenarios: As the value of assets approaches the barrier, $G$ and $G^{\alpha}$ tend toward unity so that lines 1-4 tend toward zero - and equity takes on a value equal to the expected payoff in a reorganization: $\varepsilon L_{t}$. Conversely, as the value of assets increases and the risk of default decreases, $G$ and $G^{\alpha}$ tend toward zero and the value of equity approaches the value of assets less the value of the now risk free debt plus the tax-shield: $\omega_{t}-N_{t}+\tau N_{t} \frac{r}{r-\alpha}$.

We now turn to the valuation of individual bond issues.

\subsection{Bonds}

In this section, we derive the value of a straight coupon bond. The valuation method exploits the fact that payoffs to the bond can be expressed as combinations of two building blocks. To value contracted payoffs, i.e. coupons and repayment of the principal, we use a down-and-out binary option. A down-and-out claim is one that expires worthless if the value of the underlying asset hits a given barrier prior to the expiration date - a binary option yields a unit payoff at the expiration date conditional on the underlying asset exceeding the exercise price. To capture payoffs in financial distress, one additional claim is required: the dollar-in-default claim. This claim will differ from the one in Lemma 1 in that it is subject to an expiration date (equal to the maturity of the corporate security). Consequently, it will be worth less than its perpetual counterpart.

The price formulae for the two building blocks are given in Lemmas 4-5 below. They contain a term that expresses the probabilities (under 
different measures) of the asset value $\left(\omega_{T}\right)$ not having hit the barrier prior to maturity $(\mathcal{T} \not \leq T)$ - in other words, the survival probability. To clarify this common structure, we first state those probabilities in the following lemma. ${ }^{17}$ Specifically, we will consider the two probability measures $Q^{B}$ and $Q^{G}$. They are characterized by having the money market account and the dollar-in-default claim, respectively, as numeraires.

Lemma 3 The probabilities of the event $(\mathcal{T} \not \leq T)$ (the "survival event") at $t$ under the probability measures $Q^{m}: m=\{B, G\}$ are

$$
Q^{m}(\mathcal{T} \not \leq T)=\phi\left(k^{m}\left(\frac{\omega_{t}}{L_{t}}\right)\right)-\left(\frac{\omega_{t}}{L_{t}}\right)^{-\frac{2}{\sigma} \mu^{m}} \phi\left(k^{m}\left(\frac{L_{t}}{\omega_{t}}\right)\right)
$$

where

$$
\begin{array}{r}
k^{m}(x)=\frac{\ln x+\left(\alpha+\sigma \cdot \mu^{m}\right)(T-t)}{\sigma \sqrt{T-t}} \\
\left\{\begin{array}{c}
\mu^{B}=\frac{r-\beta-\alpha-\frac{1}{2} \sigma^{2}}{\sigma} \\
\mu^{G}=\mu^{B}-\theta \sigma
\end{array}\right.
\end{array}
$$

$\phi(k)$ denotes the cumulative standard normal distribution function with integration limit $k$.

Using this lemma we obtain the pricing formulae for the building blocks, the binary option and the dollar-in-default claim, in a convenient form.

Lemma 4 The price of a down-and-out binary option (with unit payoff at $T$ conditional on no prior default) is

$$
H\left(\omega_{t}, t ; T\right)=e^{-r(T-t)} \cdot Q^{B}(\mathcal{T} \not \leq T)
$$

with the probability given by Lemma 3.

The value of the binary option thus reflects the time value of money and the risk-adjusted survival probability for maturity $T$. If the bond is riskless, $Q^{B}=1$ and the binary "option" is equal to the value of a discounted dollar.

Lemma 5 The price of a dollar-in-default claim is

$$
G\left(\omega_{t}, t \mid \mathcal{T}<T\right)=G\left(\omega_{t}, t\right) \cdot\left(1-Q^{G}(\mathcal{T} \not \leq T)\right)
$$

with probability given by Lemma 3. The result is derived in the appendix.

\footnotetext{
${ }^{17}$ The probabilities are previously known, as is the formula the down-and-out binary option in Lemma 4 (see for example Björk (1998)).
} 
The claim in Lemma 5 gives us the value of receiving one dollar in case of a reorganization before the maturity of the bond. ${ }^{18}$ Denote with $\psi$ the recovery rate for the bond and with $P$ the principal. The payout $\psi P$ can be a partial repayment, or come in the form of new securities. The value of payouts in reorganization to bondholders is $\psi P \cdot G\left(\omega_{t}, t \mid \mathcal{T}<T\right)$.

Proposition 2 A straight coupon bond. The value of a coupon bond with $M$ coupons c paid out at times $\left\{t_{i}: i=1 . . M\right\}$ is

$$
\begin{aligned}
\mathcal{B}\left(\omega_{t}, t\right)= & \sum_{i=1}^{M-1} c \cdot H\left(\omega_{t}, t ; t_{i}\right) \\
& +(c+P) \cdot H\left(\omega_{t}, t ; T\right) \\
& +\psi P \cdot G\left(\omega_{t}, t \mid \mathcal{T}<T\right)
\end{aligned}
$$

The value of the bond is equal to the value of the coupons $(c)$, the value of the nominal repayment $(P)$ plus the value of the recovery in a default $(\psi P)$. Each payment is weighted with a claim capturing the value of receiving $\$ 1$ at the respective date.

\subsection{Yield spreads}

Structural models are often criticized for generating too low credit spreads. In this section, we will argue that this critique can be misleading for technical as well as theoretical reasons.

For tractability, many models approximate actual bonds' coupons and nominal repayment with continuous coupons, infinite maturity or zero coupon debt. However, this implies different relationships between yields and prices in the model and in reality. ${ }^{19}$ For this reason, a model which produces the

\footnotetext{
${ }^{18}$ Note the relationship between Lemmas 2 and $5: \lim _{T \rightarrow \infty} G\left(\omega_{t}, t \mid \mathcal{T}<T\right)=G\left(\omega_{t}, t\right)$.

${ }^{19}$ In a model like Black \& Cox (1976), the yield is obtained as$$
y=\frac{r P}{\mathcal{B}}
$$

whereas for an actual bond, it is obtained by numerically solving the following expression$$
\mathcal{B}=\sum_{i=1}^{M-1} e^{-y \cdot t_{i}} c+e^{-y \cdot t_{M}}(c+P)
$$ 
correct price will not necessarily produce the correct credit spread. The difference in model spread and actual spread - for the same bond price - may be several hundred percent (see Reneby (1998)). In what follows, we will compute actual and predicted spreads in the same way so as allow consistent comparisons.

Another important issue is the influence of liquidity. Besides the credit risk component, actual yield spreads are very likely to include compensation for liquidity (marketability) risk. This component is not modelled in standard contingent claims models. Thus, even if a model perfectly captures the default risk of a security, it will predict yield spreads that are lower than market spreads.

There are few empirical studies of the size of the liquidity premium. Amihud \& Mendelson (1991) and Daves \& Ehrhardt (1993) investigate the yield on treasury instruments that have identical cash flows but different levels of marketability. They find that yields differ in the range of 20 to 40 basis points. However, these numbers are most likely only a lower bound for the liquidity spread for corporate bonds as they are generally less liquid than government bonds. Unfortunately, empirical studies of the corporate bond market are even more rare. Fridson \& Bersh (1993) measure liquidity in a bond issue as a function of the amount outstanding. They find that yields in the primary market increase by 40 basis points when the size of the issue decreases by $\$ 100$ million.

Delianedis \& Geske (2001) study the components of yield spreads on investment grade US corporate debt. They show that default risk can only explain a small fraction of the total spread (ranging from about $20 \%$ for $\mathrm{BBB}$ firms to around $5 \%$ for AAA firms). They argue that the remainder is mainly driven by the liquidity of the bonds and can only to a lesser extent be explained by taxes, jump risk, recovery risk and other market factors.

Perraudin \& Taylor (2002) seek to measure the liquidity premium by comparing yields on corporate bonds sorted according different liquidity proxies. They find that yields for less liquid bonds are higher by 10 to 28 basis points. Again, this estimate is a lower limit for the total spread as it does not include the differential relative to government securities. Moreover, their sample is one of high quality bonds (rated A or higher), which tend to be the most liquid.

Huang \& Huang (2002) calibrate several structural bond pricing models to historical default and recovery data, the equity premium and leverage, in order to assess the resulting default spreads. They find that for investment grade bonds, it constitutes no more than $20 \%$ of the overall spread, but that the fraction is higher for lower rated bonds. 
If, as we have argued, liquidity risk is an important determinant for bond spreads, a structural credit risk model should be expected to overprice bonds, in particular investment grade ones.

\section{Empirical Model}

In the previous section we derived the necessary pricing formulae for bonds and equity. In this section we discuss issues related to the practical implementation of our framework.

The following inputs are needed to price a bond:

- the principal amount, $P$, the coupons $c$, and the coupon dates.

- the risk free interest rate, $r$,

- the default threshold, $L_{t}$,

- the growth rate of debt (which is also the growth rate of the default threshold), $\alpha$,

- the recovery rate of the bond in case of a reorganization, $\psi$

- the rate, $\beta$, at which earnings are generated by the assets, and finally,

- the current value, $\omega$, and volatility of assets, $\sigma$.

An inspection of the equity formula in Proposition 1 reveals that three additional parameters are needed to value equity: the total nominal amount of debt, the expected deviations from the absolute priority rule as well the recovery rate for total debt - that is, the triplet $\left(N_{t}, \varepsilon, \delta\right)$.

The bond specific and term structure variables are readily observable. The default threshold will be determined endogenously as discussed above. We will rely on earlier empirical work to determine the recovery rate, $\delta$, of the aggregate debt and APR deviations parameter $\varepsilon$. The recovery rate of the bond, $\psi$, will be estimated from historical industry and seniority averages.

This leaves us with a parameter vector $(\alpha, \beta, \omega, \sigma)$ which will be estimated from equity and balance sheet data. The idea, first proposed by Duan (1994) in the context of deposit insurance, is to use price data from one or several derivatives written on $\omega$ to infer, using maximum likelihood (ML) techniques, the characteristics of the underlying, unobserved, process. In principle the "derivatives" can be any of the firm's securities that are traded in liquid markets. In practice, only equity is likely to offer a precise 
and undisrupted price series since corporate bonds tend to be liquid only immediately following issuance. Therefore, the price data used will be a series of stock prices complemented, in some of the tests, with one bond quote.

We will analyze the pricing of a non-callable straight coupon bond. This security serves as a useful benchmark which disentangles credit risk from issues such as call and put features. Furthermore it is becoming an increasingly popular financing vehicle. ${ }^{20}$

Ericsson \& Reneby (2002) evaluate this maximum likelihood approach using several theoretical models and compare it to the traditional estimation technique. ${ }^{21}$ The former clearly dominates. Moreover, the traditional approach cannot be used at all if one wants to estimate variables beyond asset value and volatility.

The maximum likelihood estimation will rely on a time series of stock prices, $\mathcal{E}^{o b s}=\left\{\mathcal{E}_{i}^{o b s}: i=1 \ldots n\right\}$. Subscript ' $i$ ' is used to index observations, in contrast to subscript ' $t$ ', which refers to a point in time in years. We require the likelihood function of the observed price variable. Defining $f(\cdot)$ as the conditional density for $\mathcal{E}_{i}^{o b s}$ gives us the following log-likelihood function for equity

$$
L_{\mathcal{E}}\left(\mathcal{E}^{o b s} ; \xi, \lambda\right)=\sum_{i=2}^{n} \ln f\left(\mathcal{E}_{i}^{o b s} \mid \mathcal{E}_{i-1}^{o b s} ; \xi, \lambda\right)
$$

where we let $\xi \equiv\{\alpha, \beta, \sigma\}$ denote the parameters needed to price the bond. To derive an expression for the density function for equity, we make a change of variables as suggested in Duan (1994):

$$
\begin{aligned}
f\left(\mathcal{E}_{i}^{o b s} \mid \mathcal{E}_{i-1}^{o b s} ; \xi, \lambda\right)= & \left.g\left(\ln \omega_{i} \mid \ln \omega_{i-1} ; \beta, \sigma, \lambda\right)\right|_{\omega_{i}=w\left(\mathcal{E}_{i}^{o b s}, t_{i} ; \xi\right)} \\
& \times\left[\left.\frac{\partial \mathcal{E}_{i}}{\partial \ln \omega_{i}}\right|_{\omega_{i}=w\left(\mathcal{E}_{i}^{o b s}, t_{i} ; \xi\right)}\right]^{-1}
\end{aligned}
$$

The equity density is now expressed as a function of $g$, the conditional density for a normally distributed variable - the log of the asset value. Note that $\mathcal{E}_{i}=\mathcal{E}_{i}\left(\omega_{i}, t_{i} ; \cdot\right)$ refers to the equity formula, whereas $\mathcal{E}_{i}^{\text {obs }}$ denotes an observed market value. The function transforming equity to asset value is

\footnotetext{
${ }^{20}$ For example, in 1982 , only $20 \%$ of the issues were non-callable, whereas in 1990 , only $20 \%$ were callable (Crabbe (1991)).

${ }^{21}$ Examples of applications of the traditional approach can be found in Jones et al. (1984) and Ronn \& Verma (1986), Ogden (1987), Delianedis \& Geske (1999), Delianedis \& Geske (2001), Eom et al. (2002) and Hull (2000).
} 
defined as $w\left(\mathcal{E}_{i}^{o b s}, t_{i} ; \xi\right) \equiv \mathcal{E}^{-1}\left(\mathcal{E}_{i}^{o b s}, t_{i} ; \xi\right)$, the inverse of the equity value function. Hence there is, given $\xi$, a one-to-one correspondence between the stock price $\mathcal{E}_{i}^{\text {obs }}$ and the implied asset value $\omega_{i}$.

By inserting (5) into (4) we obtain the log-likelihood of the vector $\mathcal{E}^{\text {obs }}$ for a given choice of $\xi$ as

$$
\begin{aligned}
L_{\mathcal{E}}\left(\mathcal{E}^{o b s} ; \xi, \lambda\right)= & L_{\ln \omega}\left(\ln w\left(\mathcal{E}_{i}^{o b s}, t_{i} ; \xi\right): i=2 \ldots n ; \xi, \lambda\right) \\
& -\left.\sum_{i=2}^{n} \ln \omega_{i} \frac{\partial \mathcal{E}\left(\omega_{i}, t_{i} ; \xi\right)}{\partial \omega_{i}}\right|_{\omega_{i}=w\left(\mathcal{E}_{i}^{o b s}, t_{i} ; \xi\right)}
\end{aligned}
$$

It is straightforward to calculate a closed form solution for $\frac{\partial \mathcal{E}_{i}}{\partial \omega_{i}}$, the "delta" of the equity formula.

The estimated parameter vector $(\widehat{\xi}, \widehat{\lambda})$ is obtained by maximizing equation $(6)$ with respect to $(\xi, \lambda)$ and subject to constraints captured by the vector $\mathbf{h}$.

$$
\begin{gathered}
\max _{\xi, \lambda} L_{\mathcal{E}}\left(\mathcal{E}^{o b s} ; \xi, \lambda\right) \\
\text { s.t. } \quad \mathbf{h}(\xi)=\mathbf{0}
\end{gathered}
$$

The constraints used are discussed in more detail below. In brief we can allow the estimation procedure to use information in market dividend yields or bond prices by constraining the model to produce theoretical values in accordance with observed ones.

Finally, an estimate of the value of assets is obtained using the inverse equity function: $\hat{\omega}_{t}=w\left(\mathcal{E}_{n}^{o b s}, t_{n} ; \widehat{\xi}\right)$. Once we have obtained the pair $\left(\widehat{\omega}_{t}, \widehat{\xi}\right)$ it is straightforward to compute the corresponding bond price estimate $\widehat{\mathcal{B}}=\mathcal{B}\left(\widehat{\omega}_{t}, t ; \widehat{\xi}\right)$ and spread $\widehat{\mathcal{S}}$. The spread is calculated solving the bond price formula in Proposition 2 for the risky yield, and subtracting the yield for the corresponding risk free bond.

\section{Simulation Study}

To investigate the small sample properties of the model and the estimation technique before bringing them to market data, we performed a Monte Carlo study. We consider two scenarios: investment grade (yield spread $64 \mathrm{bp}$ ) and 
speculative grade (yield spread 158 bp). ${ }^{22}$ In the Monte Carlo experiment, we simulate asset value paths consistent with the chosen scenario.

For each stock price path, we estimate - with and without bond price information - the current asset value and model parameters and use these to price a 10 year bond. Finally, we calculate the estimated yield spread and compare it to the true yield spread.

With bond price information, estimation is very efficient: the spread estimator is unbiased with a $1 \mathrm{bp}$. standard deviation in both firm scenarios. Without bond prices a slight small sample bias becomes apparent - the model underestimates the yield spread by $6 \mathrm{bp}$. ( $t$-stat: 1.34) and $11 \mathrm{bp}$. ( $t$-stat: 2.33) in the investment grade and speculative grade firm scenarios, respectively. The standard deviations of the spread errors increase to $19 \mathrm{bp}$. and 33 bp.

Comparing high and low yield debt we note that even though the spread error increases as the yield is higher, the relative error actually decreases. The reason is that the stock price is more volatile when the yield is higher, and so conveys more information about the parameters of the underlying asset value process and the firm's default risk.

\section{Data}

Our database consists of bond prices and characteristics, firm balance sheet information, equity prices and term structure data. As a starting point we took the FISD bond database which contains data for bonds that were part of the Lehman Brothers indices. It contains monthly prices for a large array of fixed income securities. We chose to focus exclusively on industrial bonds for firms based in the US during the coverage of our version of the database, i.e. between January 1994 and February 1998.

An important advantage of the FISD database is that it distinguishes between trader quotes and matrix quotes. As matrix quotes may not provide a reliable estimate of the price at which a trade could take place we chose to eliminate them.

To concentrate on credit risk and avoid dealing with option features we eliminated all callable and putable bonds as well as those with sinking fund features. Furthermore, as we wish to analyze both the time series as well as

\footnotetext{
${ }^{22}$ The bond specific parameters were: $T=10, c=4 \%, \psi=40 \%$. The firm specific parameters were: $\alpha=3 \%, \sigma=20 \%, \beta=3 \%, r=6 \%, \varepsilon=3 \%, \delta=40 \%, \tau=20 \%$, $N=1000$. The investment grade firm's asset value was 1400 , providing a leverage of $57 \%$ and an equity volatility of $37 \%$, whereas the speculative grade firm's asset value was 1050 , providing a leverage of $71 \%$ and a volatility of $47 \%$.
} 
the cross-sectional aspects of corporate bond yield spreads, we eliminated all bonds with less than 12 consecutive monthly observations. In addition, we eliminated bonds for which it was clear that prices were stale (e.g. the same quote for more than two months despite changing risk free interest rates), where data entry errors were apparent or for which corresponding equity or balance sheet data was simply not available. Two additional firms were dropped because of convergence problems in the estimation procedure. In the end we were left with 141 bond issues by as many firms; the number of monthly price observations we have on each bond ranges from 12 to 50. In total there are 5594 bond price observations on which our pricing performance and model specification analysis is carried out. This can be compared to the sample used by Jones et al. (1984) which consists of a total of 305 prices from 27 firms, and that of Eom et al. (2002) which encompasses 182 bond prices from as many firms.

The FISD database also provides all the characteristics of the individual bonds such as coupon, maturity and ratings. However, we also require information about the liability structure of the firm. As mentioned above, we use the aggregate nominal debt of the firm as an input to derive the market value of equity and thus give us a model for default probabilities. Our empirical measure of the total debt of the firm is the total liabilities as reported in firms' EDGAR filings compiled and provided by Mergent FIS.

In addition to this, we require daily market values for the outstanding equity as well as information about the risk free interest term structures over time. This data was obtained from DATASTREAM.

All the bonds we consider are unsecured bullet bonds. Table 2 lists descriptive statistics for the 141 bonds and the issuing firms. We also provide statistics for subgroups across rating and maturity. Note that FISD corporate bond data is dominated by investment grade issues. ${ }^{23}$ Thus the subcategory of speculative grade bonds - rated BB or lower - make up only slightly more than $10 \%$ of the total bond price data at 588 observations. We decided to also split the data into two groups which we refer to as "high" (rated A or higher) and "low" (rated BBB or lower) rated issues.

The average book leverage is $41 \%$ and the average equity volatility during the 250 trading days preceding a bond quote is $28 \%$. Bond maturities range from 1 to 30 years and coupon rates from $5.6 \%$ to $10.88 \%$. The average

\footnotetext{
${ }^{23}$ The term investment grade applies to bonds with an S\&P rating higher than $\mathrm{BB}+$. The numerical conversion reported in Table 1 works as follows: a 1 represents AAA+, 2 AAA and so on. The lowest investment grade bond has a numerical rating of 11 (BBB). The lowest (highest numerical) rating in the beginning of our sample is a 16 which corresponds to a B.
} 
numerical rating (8) corresponds to a A- rating. This produces credit spreads from 10 to 1589 basis points, the average being 89 .

The recovery rate for individual bonds, $\psi$, are set as a function of industry and seniority. We categorize the 141 companies in our sample according to the SIC codes used by Altman \& Kishore (1996) and assign the bonds recovery rates accordingly, allowing for seniority. Finally, we set the deviations from the absolute priority rule to $5 \%$ of the asset value in default.

The growth rate of debt $(\alpha)$, the earnings $(\beta)$, the volatility of the asset value $(\sigma)$ and the values of the assets $\left\{\omega_{t}\right\}$ are then estimated using maximum likelihood.

\section{Results}

We present the results in several steps. First, before discussing the pricing performance of the model, we briefly examine the estimated firm specific parameters. Second, we discuss the estimation of the model using only stock prices $\left\{\mathcal{E}_{i}^{o b s}: i=1 . . n\right\}$ and using it to predict the bond price at $t_{n}$. Then, we estimate the model using the same stock prices plus the bond price at $t_{n}$ and value the bond out-of-sample. To compare our findings with other studies, we attempt to price the bond the following month only (at $t_{n+1}$ ). Then we provide an extended version of the same theme; we price the bond during a long period of time (i.e. up to 50 months, or 5 years, after $t_{n}$ ) using only updated market capitalizations, risk free term structures and balance sheet data. All of these different approaches have different motivations that will be discussed for each experiment as we proceed.

We then turn to an analysis of the correlations between yield spreads and the risk free term structure, and then consider the valuation of bond portfolios. Once the pricing performance of the model has been analyzed we study the model's prediction errors by regressing them against a variety of firm specific, bond specific and economy wide variables. This is done for errors both in predicted levels and changes in yield spreads.

\subsection{Estimation of firm specific variables and parameters}

An advantage of a structural approach to valuing corporate liabilities, is that in the process one has to estimate parameters which give rise to quantities that can be directly related to observable measures. Furthermore, one can infer other quantities which are difficult to observe but likely of greater

economic interest. Examples include asset volatility, the market value of the firm, expected bankruptcy costs, the value of tax shields as well as 
default probabilities. An in-depth discussion of all variables that can be estimated lies outside the scope of this paper. We focus our attention on the estimation of the debt growth rate, the cash flow rate, asset volatility, the default threshold and firm value. The results are summarized in Table 2 .

We observe some cross-sectional variation in the estimates of the debt growth rate $\alpha$, the asset volatility $\sigma$, and the cash flow rate $\beta$. It is noteworthy that although it is difficult to confront these estimates with observed benchmarks, they appear economically reasonable. Asset volatilities range from $3.8 \%$ to almost $110 \%$ with an average of $26 \%$. They are also strongly negatively correlated with book leverage $(\rho=-0.61)$, indicating that firms with high business risk tend to operate with lower leverage. The debt growth rate ranges from $0 \%$ to $33 \%$ per annum with an average of just over $8 \%$. This metric is negatively related to firm leverage $(\rho=-0.65)$, consistent with high leverage firms having less potential to increase debt.

An interesting pattern appears when we look at estimated asset volatilities over time. Figure 1 plots the average estimate of $\sigma$ between 1994 and early 1998. Campbell \& Taksler (2002) argue that the relative underperformance of corporate bonds relative to equities during the late nineties can be explained by the systematic increase in idiosyncratic equity volatilities. We see the same pattern in our sample, and may take the explanation one step further. Figure 1 shows a dramatic increase in average estimated asset volatilities over time. In addition book leverage, if anything, decreases for the firms in our sample during this period. Hence our results support the findings of Campbell \& Taksler (2002) and point out that the cause of increased idiosyncratic equity volatilities during this period is not leverage related but rather due to an increase in the firm specific levels of business risks.

\subsection{Estimation without bond prices}

In this section, we address the pricing of bonds using market prices from stocks only. Specifically, we use the model to price the bond on the first day its price appears in our sample (the pricing date). To this end, we use a sample of 250 stock prices prior to and including the pricing date. In order to exploit the additional information contained in dividends we constrain the yield implied by the model to coincide with the market yield. The dividend yield is calculated from the average dividend during those 250 trading days. The constraint $\mathbf{h}$ of the likelihood function is that the theoretical dividends 
during the sample period

$$
D I V^{\text {theo }}(\xi)=\int_{t_{1}}^{t_{n}} D I V\left(\omega_{s}, s ; \xi\right) d s
$$

should equal actual dividends. Thus

$$
\mathbf{h}(\xi, \lambda)=D I V^{\text {obs }}-D I V^{\text {theo }}(\xi)
$$

The results of the test are presented in Table 3 . The relative pricing error is somewhat higher than $4 \%$ and the model tends to underpredict the yield spread by about $70 \%$ on average. The direction of this error is the same, although larger in magnitude, as for the implementations of the Merton (1974) and Geske (1977) by Eom et al. (2002). The direction is the opposite to what Eom et al. (2002) find for the models by Longstaff \& Schwartz (1995) and Collin-Dufresne \& Goldstein (2001). Such a distinct underestimation of yield spreads may at first glance appear disappointing. However, recall that the model only captures default risk and that, as discussed above, a large fraction of the spread may be induced by liquidity. Huang \& Huang (2002) show that default risk may contribute to only about $20 \%$ of yield spreads for investment grade bonds, although this fraction increases for more risky bonds. Our model's relative spread errors for investment grade bonds almost coincides with the fraction predicted by Huang \& Huang (2002), and the errors decrease as bonds become more risky.

The standard errors of our relative spread errors are smaller than for the best performing model evaluated by Eom et al. (2002) and less than a third of the standard errors for less precise implementations.

\subsection{Estimation with bond prices}

Incorporating bond price information into the estimation procedure provides crucial additional information. Having less upside potential, bond prices are, relative to stock prices, more sensitive to financial risk than to asset risk. Moreover, the yield spread of a bond, which has a fixed maturity, contains information about the term structure of default probabilities - something that stocks, with infinite maturity, are less likely to convey. Therefore, we expect the maximum likelihood estimation to improve substantially when we include a bond price in the data set.

When we add bond price information, we simply extend the constraint 
vector $\mathbf{h}:^{24}$

$$
\mathbf{h}(\xi)=\left[\begin{array}{c}
D I V^{o b s}-D I V^{\text {theo }}(\xi) \\
\mathcal{B}^{o b s}-\mathcal{B}\left(\omega_{t_{n}, t_{n}} ; \xi\right)
\end{array}\right]
$$

A potential drawback of thus constraining the model to price the bond correctly in-sample, is that we may effectively overestimate credit risk to make the model capture other sources of risk, such as illiquidity. ${ }^{25}$ As a result of overestimating the default risk of a bond, we may make predicted spread changes more sensitive to changes in stock prices than it should be. However, it turns out that the changes in spreads predicted by our model with or without bond price information are similar and no significant oversensitiveness is detected.

When incorporating bond price information in practice, we can think of a situation where the bond is actively traded when issued and hence that the observed price at that time can be used to draw inferences about the creditworthiness of the firm. However, after the first month, liquidity typically declines and the bond prices quoted in the market are not reliable; we need a model to predict the credit spread.

\subsubsection{One month out-of-sample prediction}

We now estimate the model using stock prices as in section 6.2 plus the last observed bond price during the stock sample period. Then, we attempt to predict the bond price the following month (at time $t_{n+1}$ ). This prediction is based on the observed stock price at $t_{n+1}$ and the parameter vector estimated at $t_{n}$. This is then repeated for the subsequent month; i.e. estimating the model at $t_{n+1}$ and predicting the bond price at $t_{n+2}$. By thus rolling the estimation forward including all available observed prices for all 141 companies, we arrive at a sample size of 5452 predictions. The outcome of the test is presented in Table 4.

The mean predicted error is -2 basis points ( $-2 \%$ of the total spread) and thus our estimator now appears unbiased for all practical purposes. The standard deviation of the error is down to $19 \mathrm{bp}$ (18\%). Compared to the previous numbers, when we had no bond price information, we observe a marked improvement, as expected. We also note that even though the absolute errors are higher for speculative than investment grade debt, the

\footnotetext{
${ }^{24}$ Equivalently, we could have extended the likelihood function.

${ }^{25}$ The same effect would of course show up in any credit risk model using bond prices as inputs, such as the reduced form models.
} 
relative performance is better for higher yield debt; this is in line with the outcome of the Monte Carlo experiment presented earlier.

Again we can compare with the findings of Eom et al. (2002). When they conduct a similar test to ours with the Merton model - incorporating bond prices and predicting one month ahead - they also find a marked improvement. ${ }^{26}$ Instead of underestimating the spread, as the model does without bond price information in the estimation process, it then overestimates the spread by about $12 \%$ with a standard deviation of $72 \%$, almost four times higher than for our model.

We can also compare our figures with those found by Bakshi et al. (2001) (BMZ), who test a set of reduced form models with stochastic interest rates. BMZ extend the basic framework into several models by also including firm specific variables such as leverage, book-to-market or the stock price. The models are estimated using the firm specific variable, the risk free term structure and at least 12 observations on bonds issued by the firm. They predict prices for firms' bonds one month out-of-sample. The predictions are based on the out-of-sample value of the firm specific variable, the out-ofsample term interest rate and the parameter vector estimated in the previous quarter. Hence this setup is comparable to ours.

BMZ report an average absolute percentage pricing error between $1.4 \%$ and $1.8 \%$ for all models and all rating classes. In contrast, our average absolute relative pricing error is about $0.7 \%$. They find, like us, that the errors in both prices and spreads tend to increase as the credit rating worsens. Their average absolute spread error increases from about 24 basis points for AA rated debt to 32 basis points for $\mathrm{BBB}$ debt. Our average absolute spread error is 11 basis points for all bonds (compared to their 28 basis points) and reaches 30 basis points for speculative grade debt. They do not however, report percentage spread errors. Our relative spread errors decrease as the credit ratings worsen from about $3 \%$ to $1 \%$.

It seems that our model compares fairly well to the reduced form models of BMZ. One interesting aspect of their study is that their approach performs less well when the stock price is used as firm specific variable, i.e. when it incorporates (part of) the information that is crucial to our model. It thus appears that a structural model for the link between stock prices and bond prices improves performance.

It is worth noting that almost any model would likely produce a relatively

\footnotetext{
${ }^{26}$ They incorporate bond price information by using as their estimate of the asset volatility the value which gives the correct bond price one month prior to the valuation date. They refer to this as the "bond implied volatility".
} 
low mean error when bond price information from the immediately preceding month is included. As Eom et al. (2002) point out when discussing their results for the Merton model : "While [including bond prices makes the model] more effective in predicting future prices [...], it is not clear that [the estimated] volatility is so much a measure of volatility as a catch-all for errors in the structural model." Although this may be less of a problem in our test as we use time series of stock prices to estimate the model parameters, we can address this issue by using the model predict bond price changes.

To our knowledge, the ability to predict yield spread changes is a criterion to which models of defaultable bond valuation have not yet been subjected. As we will show, and as has been shown by Collin-Dufresne et al. (2001), this is a much more challenging task. Table 6 reports the results for this question for estimation with bond prices. ${ }^{27}$ Although the errors in spread changes are relatively small ( -2 basis points for all bonds with an average absolute spread change error of 11 basis points), the correlation between actual changes and predicted changes is low at $13 \%$ overall (Panel A). The correlations for highly rated issues and lower rated ones are not significantly different. It is only when we look at the smaller subsample of speculative grade bonds that the correlation increases. In fact it is almost twice as high. This suggests that the model performs better when default risk is a more important factor.

At this point it is tempting to hypothesize that the poor predictive ability of the model is due to noise in the data. To examine this issue we split our sample of changes into three categories: those less than 15 basis points, those larger than 15 basis points and those larger than 30 basis points. The standard deviation of the predicted spread changes in our sample is about 15 basis points, not far from that of the realized spread changes at 17 basis points. We then regress the actual market spread changes $\left(S C^{\text {market }}\right)$ on the model's predicted change $\left(S C^{\text {model }}\right)$ according to the following equation

$$
S C_{i, t}^{\text {market }}=a+b \cdot S C_{i, t}^{\text {model }}+\varepsilon_{i, t}
$$

The results are reported in panel B of Table 6 . When all changes are considered we find an estimated $b$ of 0.28 and an adjusted $R^{2}$ of $6.30 \%$. This stands in stark contrast to the results for the subsample of changes less than 15 basis points. The estimated $b$ then falls to 0.05 and the $R^{2}$ to just over $1 \%$. As the cut-off size of the spread changes increases the coefficient estimate of $b$ approaches 1 ( 0.72 for changes larger than 15 basis points and 0.94 for those larger than 30 basis points) and the adjusted $R^{2}$ increases to almost

\footnotetext{
${ }^{27}$ Results for estimation without bonds are very similar.
} 
$13 \%$ for the largest changes. Figure 3 provides a compelling visual presentation of this result. A plausible explanation for these results is that large changes in spreads are driven mainly by changes in the default risk of the issuer whereas smaller changes are due to noise or other factors that impact bond yield spreads. Related evidence is provided by Liu et al. (2002) who find that although the main component of swap spreads is default risk, most of the variation in these spreads is driven by changes in liquidity premia. As we will see later when we regress spread errors on firm specific and economy wide variables, those emanating from small changes can be explained to a large extent by proxies for liquidity and aggregate market variables. For larger changes, the errors do not seem to be liquidity related at all and can be explained only marginally by other variables.

\subsubsection{Longer horizon out-of-sample prediction}

We will now repeat what is essentially the same experiment as above, except that we look at bond prices further out-of-sample. We will fix the model's parameters to their initially estimated values and only allow updating of observed quantities such as stock price, book leverage and term structure data. This is clearly likely to generate larger errors than a more pragmatic approach of reestimating the model for each monthly valuation date.

The estimation of the parameters is done exactly as before (incorporating bond price information at $t_{n}$ ), but instead of predicting the bond price at just $t_{n+1}$, we predict the bond price at $\left\{t_{n+j}: j=1 . . J\right\}$ where $J$ is equal to the total number of bond price observations available (the prediction horizon). Therefore, we also need the out-of-sample observations on the stock price $\left\{\mathcal{E}_{n+j}^{o b s}: i=1 . . J\right\}$. I.e. the prediction at time $t_{n+j}$ is made using $\mathcal{E}_{n+j}^{o b s}$ (and the parameter vector estimated at $t_{n}$ ).

The results of the test are presented in Table 5 . The correlation between the predicted and actual yield spread is on average 34\%, and $57 \%$ in the speculative subsample. This figure suggests that the model indeed captures an important fraction of the actual changes in the value of bonds using stock price information only.

The average (across firms and pricing dates) prediction error is now $-18 \%$ of the total yield spread, and thus the model overprices bonds further out of sample. Compared to the one-month predictions in table 4, the accuracy of the model's spread predictions has decreased as well: the average crosssectional absolute error has increased from $18 \%$ of the spread to $47 \%$. Recall, however, that we are now attempting to predict bond prices up to 5 years after the model's parameters were estimated. The figures 2 at the end of 
this paper allow a visual inspection of the performance of our model.

One apparent explanation for overpricing over longer horizons, would be that, as reported above, business risk (asset volatilities) on average have increased over the sample period (figure 1). Since we do not re-estimate the model, this source of increased credit risk will not be captured and spreads will be underestimated.

\subsection{Correlations between risk free interest rates and corpo- rate bond yield spreads}

Longstaff \& Schwartz (1995) predicted and documented a negative correlation between credit spreads and the overall level of the term structure. Duffee (1998) provides a more in-depth empirical study of this question. He finds that changes in corporate bond yield spreads are systematically negatively related to both increases in the level of the three month US Treasury yield and the slope of the Treasury yield curve. The relationships between both the short term Treasury yield and slope are stronger for lower quality bonds. Overall the same picture emerges in our dataset - see the leftmost columns labeled Market Spread Changes in Table 7 - although perhaps not as distinct as in Duffee (1998). This is likely due to the longer time window covered by his data.

It might appear natural that to capture this correlation, a model would have to explicitly allow for stochastic interest rates. However, it may also be the case that the correlation can be generated by our static interest rate framework as interest rate inputs are updated in our estimation procedure. To address this issue, we repeat the exercise above, but this time with the model spread changes as dependent variable. Our findings are reported in the rightmost columns of Table 7 - Model Spread Changes.

The parameter estimates are of the same order of magnitude for the model and market spreads. For long maturity bonds and those with a high credit rating the results are essentially the same for both measures of the spread. In cases where parameter estimates differ in sign, they are not significantly different from zero. We conclude from this exercise that the sensitivities of corporate bond yield spreads to the risk free term structure of interest rates generated by our model are not dissimilar to those observed in the market spreads. This suggests that it may not be a priority to extend our approach to allow for stochastic interest rates. 


\subsection{Valuing bond portfolios}

We have so far considered the performance of our approach on individual bonds. We shall now see how well one can expect it to perform when valuing bond portfolios of different sizes. If model errors are cross-sectionally independent, the pricing of bond portfolios would turn out much more efficient than the pricing of individual bonds.

Figure 4 illustrated how the standard deviation of the relative pricing error decreases as portfolio size increases. The thin solid line represents the standard deviation for estimation without bond prices, and the thick solid line that for estimation with bond prices. In both cases efficiency is improved substantially, even for small portfolios. A portfolio of 20 bonds produces a marked decrease in standard deviation - for example the standard deviation for estimation without bonds is four times lower. Expanding it beyond this size has little effect.

We can compare achieved efficiency with the hypothetical efficiency obtained assuming independent errors. In figure 4 the hypothetical efficiency is given by the dotted lines. It seems that errors without bond price information are more successfully diversified away than errors based on estimation with bond prices; however, one should keep in mind that the former is biased whereas the latter is not.

Diversified estimation errors in either case attain the same maximum efficiency: $0.29 \%$ standard deviation of the relative pricing error. The standard deviations before diversification were $0.80 \%$ and $2.32 \%$ for estimation with and without bonds, respectively. Apparently, a large fraction of the model's errors are diversifiable, but a non-negligible cross-sectional component remains. Figure 5 shows how this component evolves over time. Even though it may at first glance appear random, note that the corresponding hypothetical standard deviation assuming independent errors $(0.07 \%)$ is far too small to generate such swings. In the next section, we will seek to explain the cross sectional error component.

\subsection{Error analysis}

Up to this point we have shown that the performance of the structural bond pricing approach suggested in this paper - together with the estimation approach used - appears quite successful when compared to earlier studies. The errors we obtain are typically smaller and less variable than previously reported. Nevertheless, our study points to weaknesses of the model - notably, overpriced bonds when no bond prices are incorporated in the infor- 
mation set. Understanding the errors of our approach may provide insights that can be used to design improved models for the valuation of credit risky securities.

\subsubsection{The explanatory variables}

To understand the source of the errors in the model's bond price predictions, we have chosen to examine the relationship between the spread errors and a set of bond specific, firm specific and economy wide variables. These are listed in Table 8.

First consider the bond specific variables. We do not have a prior as to the relationship between the rating and the model errors insofar as the rating measures credit risk only. If our model fully captures default risk then the rating should add no further information. However, the rating may proxy for other factors such as market segmentation effects. There may be different clienteles in the markets for speculative and investment grade debt respectively. If these clienteles differ in size then rating may in fact proxy for liquidity. Suppose, as seems likely, that there are more active investors in the market for investment grade debt. Then a higher rating (lower numerical rating) indicates higher liquidity. If we believe this interpretation then we would expect our model to yield larger errors for speculative grade bonds as they would tend to be less liquid.

A more direct proxy for liquidity risk is the age of a bond. Younger bonds tend to be more liquid, and in particular just issued ones. Hence we would expect our model to perform better for just issued bonds. However, a problem with age is its negative correlation with maturity. If our model performs better for on-the-run bonds it could instead suggest that we do better in valuing longer bonds. Nevertheless, even this second interpretation is consistent with a liquidity problem: Ericsson \& Renault (2000) show that the liquidity component in corporate bond yield spreads should be smaller for long bonds. We try to separate these two effects by including an "onthe-run" dummy, rather than age, together with maturity.

The size of an issue - amount outstanding - is yet another variable that has been suggested to proxy for bond liquidity. A larger issue would intuitively be more liquid. The coupon of a bond will reflect the credit rating as well as the level of the interest rates at the point in time the bond was issued.

Second, consider the firm specific variables. The sum of book value of debt and market capitalization is used to measure firm size and the ratio of book value to size to measure leverage. We also include historical stock 
return and volatility as explanatory variables.

Third and finally, we incorporate several economy wide variables. In order to examine the impact of liquidity effects we consider three proxies. First and foremost, we use the difference between the yields on the on-therun and off-the run Treasuries for four maturities (2, 5, 10 and 30 years). We presume that if investors are willing to pay a premium for holding the most liquid Treasury bond (as would be the case in a "flight to quality" episode such as during the Russian default crisis) then it is likely that the liquidity spread on corporates is higher as well. A related but less direct measure of market-wide liquidity is the Federal Reserve Bank's supply of short term funds, money of zero maturity. A high supply could correspond to a liquid short term fixed income market, lower spreads and thus lower errors. On the other hand, the Fed's decisions are driven by market conditions. For example, an increased supply could be a response to low liquidity, and therefore be correlated with illiquid market conditions. A third related variable has recently been suggested by Newman \& Rierson (2002). They argue that demand curves for corporate debt may be downward sloping, and that therefore the issuance activity may impact on the spreads of outstanding corporate bonds. ${ }^{28}$ We expect that, if significant, the total issuance of corporate debt should increase market spreads and thus our yield spread errors.

The VIX (CBOE volatility index) is a measure of implied volatility on US index options. It may be viewed as a proxy for the volatility of the US stock market as a whole. We use this variable together with the return on the S\&P 500 index and the default premium (the difference between Moody's Aaa and Baa corporate bond yield indices) as diagnostics of overall market conditions. Lastly, we investigate if the model spread errors are related to term structure variables: we use the ten year yield to measure its level and the difference between ten and two year yields to measure the slope.

As a first check on our explanatory variables, we ran a regression with the market spread as the dependent variable. ${ }^{29}$ Of the bond specific variables, low quality rating is strongly associated with higher spreads. Longer bonds and bonds in small issues also have higher spreads. The latter observation is consistent with the liquidity story given above. Furthermore, highly leveraged and volatile firms have higher spreads, and so have bigger firms. Of the economy wide variables, the difference between the yields on

\footnotetext{
${ }^{28}$ We compiled this data using prices at issue of corporate bonds included in the Fixed Income database supplied by LJS Information Services.

${ }^{29}$ The regression is pooled, multivariate OLS with White (1980) standard errors and random intercepts. Results are available upon request.
} 
on- and off-the run Treasuries of maturities 2, 5 and 10 years have a positive effect on market spreads, and thus confirms the hypothesis that the liquidity premium in the corporate bond market at least to some degree is determined by liquidity premium in the Treasury market. High market volatility is associated with lower market spreads. It is noteworthy that the default premium - the aggregate market credit risk spread - does not turn out significant in a multivariate regression. Finally, the slope of the risk free yield curve is associated with lower spreads, as discussed in section 6.4.

\subsubsection{Error analysis results}

We run pooled multivariate regressions on errors resulting from pricing without bond prices. The dependent variable is the spread error $S E$, which is negative on average. ${ }^{30}$ The regressions are also run on two subsamples; one consisting of all positive errors, the other of all negative errors. It is not unreasonable to expect that they should be affected by different variables. Table 9 presents the results from the multivariate regressions.

Turning first to the bond specific variables, the model underpredicts spreads less for investment grade, on-the-run bonds from large issues. This is in line with the idea that these bonds are more liquid, decreasing the liquidity spread. We also note that the effect is more pronounced for negative errors, as one would expect if underprediction is caused by liquidity premia in the spreads.

All the firm specific explanatory variables are significant. For highly levered firms, the model's errors are larger in magnitude - however, leverage is a proxy for the market spread and the relative spread errors are smaller. The model underprices small firms' spreads more, but again the relationship is reversed for relative errors. Furthermore, following low returns and high volatility, the model tends to predict higher spreads. The latter effect could be explained by the estimation procedure, which has a slight tendency to overestimate the asset volatility (and therefore spreads) when historical stock return and volatility are high. ${ }^{31}$

Of the economy wide variables, we first note that although several variables have explanatory power, the power almost entirely comes from explaining overpricing (i.e. negative spread errors). The direct liquidity proxies -

\footnotetext{
${ }^{30}$ We also ran regressions with the relative spread error, $R S E$, as dependent variable; these results are not displayed but available upon request.

${ }^{31}$ An unusually high realized asset volatility results in an unusually high historical stock volatility which, in turn, translates into an excessive asset volatility estimate (see Ericsson \& Reneby (2002)).
} 
the liquidity spreads in the Treasury market - have a negative effect on the (negative) errors, consistent with the liquidity hypothesis: the higher the liquidity spread, the worse the overpricing.

Furthermore, low return and volatility of the market implies that the model's negative errors are smaller in magnitude. Contrarily, high interest rates and a steep term structure implies that the negative errors are larger in magnitude.

In summary, we find that negative and positive errors are to a large extent driven by different variables; in particular, variables that measure the liquidity premium explain underpredicted, but not overpredicted, spreads. It seems plausible that positive errors to a large extent are explained by noise, whereas negative errors are driven by factors that a pure credit risk model, such as ours, does not capture.

We also sought to explain the bond portfolio error that could not be diversified away as described in section 6.5. The dependent variable is now the relative pricing error (from estimation with bond prices) of the portfolio of all bonds, as plotted in figure 5 . The explanatory variables are the economy wide variables only. We find that the slope of the yield curve, the realized return of the S\&P 500 and the 10 year Treasury liquidity spread has an impact on our pricing errors. ${ }^{32}$ The sign of the slope coefficient is in line with the one found for the spread regressions, whereas the market return comes with the opposite sign; high market return is associated with more positive pricing errors. Note however that a more positive pricing error not necessarily corresponds to a more negative spread error. The impact of the Treasury liquidity spread on the portfolio errors - positive - provides a robustness check on our findings for individual bond spreads. It lends further support to the idea that an important source of model error is the absence of a model for liquidity risk.

Next, we consider the errors arising when using our model to predict changes in corporate bond spreads. Since this is a more difficult task than explaining levels of spreads, analyzing these residuals may provide additional information about the shortcomings of our model. Table 10 reports the results for three different regressions. The first one displays how well changes in the explanatory variables can explain the errors in our model's change predictions. More or less the same explanatory variables are significant for explaining these errors as the errors in level predictions.

As discussed above, our model is better able to predict the larger changes. This led us to suggest that the smaller changes might not be related to

\footnotetext{
${ }^{32}$ For brevity these results are not reported.
} 
default risk as such. The last two regressions in this table report the results when our sample of yield spread change errors is split into large and small changes (larger or smaller than 15 basis points). For the small changes eight out of seventeen explanatory variables are significant. In contrast, for the larger changes only one is, the change in the slope of the risk free term structure. Hence the results strengthen our previous hypothesis that small spread changes are mainly driven by changes in liquidity. For the larger ones, on the other hand, the predictive power of the model's spread change is substantially stronger and any residual error is much more likely to be due to noise in the data.

\section{Conclusion}

We have presented an empirical study of a new structural approach to valuing corporate bonds. Our model separates the treatment of firms' aggregate capital structures and the particular bond that is to be priced. This allows us to combine a tractable model of equity with a realistic model for bonds. We implement the model using a maximum likelihood method developed by Duan (1994) on a large sample of US corporate bonds. This method has been shown by means of Monte Carlo simulation to be superior to commonly used alternatives, yet has to date not been applied to market data. As inputs to the estimation, we use stock prices, dividend yields, balance sheet and risk free term structure information. In addition, we model the recovery rates for individual bonds as a function of seniority and industry.

The overall performance of our approach is good relative to past attempts at implementing structural bond pricing models. Moreover, it compares well to recent tests of reduced form models, which tend to be viewed as superior to structural models in terms of empirical performance.

We also investigate the ability of the model to price bond portfolios and find that the greater part of the errors from individual bonds are diversifiable. However, there is a non-negligible component that appears systematic. An analysis of the spread errors obtained with our approach reveals that negative errors (when the model overprices bonds) are less likely to be noise driven than positive errors. An important determinant of the negative errors are liquidity proxies like the spread between on and off-the-run Treasury bonds. In addition, errors in predicting small, but not large, spread changes are explained by liquidity proxies. We conclude that liquidity risk is an important determinant of corporate bond spreads.

In sum, our results lead us to be optimistic about the prospects of struc- 
tural modelling of credit risk as a practical tool in finance. However, models clearly lack one or several vital components. A challenge for future research is thus to develop tractable structural bond pricing models that are able to empirically capture and distinguish default risk and for example liquidity risk. 


\section{References}

Altman, E. I. \& Kishore, V. M. (1996), 'Almost everything you wanted to know about recoveries on defaulted bonds', Financial Analysts Journal pp. 57-64.

Amihud, Y. \& Mendelson, H. (1991), 'Liquidity, maturity, and the yields on U.S. treasury securities', Journal of Finance 46, 1411-1425.

Anderson, R. \& Sundaresan, S. (1996), 'Design and valuation of debt contracts', Review of Financial Studies 9, 37-68.

Anderson, R. \& Sundaresan, S. (2000), 'A comparative study of structural models of corporate bond yields : An exploratory investigation.', Journal of Banking and Finance 24, 255-269.

Bakshi, G., Madan, D. \& Zhang, F. (2001), 'Investigating the sources of default risk: Lessons from empirically implementing credit risk models', Working paper University of Maryland.

Björk, T. (1998), Arbitrage Theory in Continuous Time, Oxford University Press.

Black, F. (1985), 'Comment on jones, e.p., s.p. mason and e. rosenfeld 1985 "contingent claims valuation of corporate liabilities: Theory and empirical tests"', in Friedman, B.M. "Corporate Capital Structures in the United States", NBER Project Report, University of Chicago Press pp. 262-263.

Black, F. \& Cox, J. C. (1976), 'Valuing corporate securities: Some effects of bond indenture provisions', Journal of Finance 31, 351-67.

Black, F. \& Scholes, M. S. (1973), 'The pricing of options and corporate liabilities', Journal of Political Economy 7, 637-54.

Campbell, J. T. \& Taksler, G. B. (2002), 'Equity volatility and corporate bond yields', working paper Harvard University .

Collin-Dufresne, P. \& Goldstein, R. (2001), 'Do credit spreads reflect stationary leverage ratios?', Journal of Finance $\mathbf{5 6 .}$

Collin-Dufresne, P., Goldstein, R. \& Martin, S. (2001), 'The determinants of credit spread changes', Journal of Finance 56, 2177-2207.

Crabbe, L. (1991), 'Callable corporate bonds: A vanishing breed', Wasington D.C.: Board of Governors of the Federal Reserve System . 
Daves, P. R. \& Ehrhardt, M. C. (1993), 'Liquidity, reconstitution, and the value of U.S. treasury strips', The Journal of Finance 48, 315-329.

Delianedis, G. \& Geske, R. (1999), 'Credit risk and risk neutral default probabilities: Information about rating migrations and defaults', Working Paper UCLA .

Delianedis, G. \& Geske, R. (2001), 'The components of corporate credit spreads: Default, recovery, tax, jumps, liquidity, and market factors', working paper UCLA .

Duan, J.-C. (1994), 'Maximum likelihood estimation using price data of the derivative contract', Mathematical Finance Vol 4. No. 2 April pp. 155167.

Duffee, G. (1999), 'Estimating the price of default risk', Review of Financial Studies 12, 197-226.

Duffee, G. R. (1998), 'The relation between treasury yields and corporate bond yield spreads', Journal of Finance 53, 2225-2241.

Duffie, D. \& Singleton, K. (1999), 'Modeling term structures of defaultable bonds', Review of Financial Studies. 12, 687-720.

Eom, Y. H., Helwege, J. \& Huang, J.-Z. (2002), 'Structural models of corporate bond pricing: An empirical analysis', working paper .

Ericsson, J. \& Renault, O. (2000), 'Liquidity and credit risk', working paper $L S E$.

Ericsson, J. \& Reneby, J. (1999), 'A note on contingent claims pricing with non-traded assets', Stockholm School of Economics working paper no. 314

Ericsson, J. \& Reneby, J. (2002), 'Estimating structural bond pricing models', working paper McGill University .

Fan, H. \& Sundaresan, S. (2000), 'Debt valuation, renegotiations and optimal dividend policy', Review of Financial Studies 13, 1057-1099.

Fisher, L. (1959), 'Determinants of the risk premiums on corporate bonds', Journal of Political Economy 67, 217-37. 
Fridson, M. S. \& Bersh, J. A. (1993), 'Measuring liquidity premiums in the high yield bond market', Extra Credit . (Published by Merrill Lynch Capital Markets).

Fridson, M. S., Garman, M. C. \& Wu, S. (1997), 'Real interest rates and the default rate on High-Yield bonds', The Journal of Fixed Income pp. 29-34.

Fridson, M. S. \& Kenney, J. F. (1994), 'How do changes in yield affect quality spreads?', Extra Credit pp. 4-13. Published by Merrill Lynch Capital Markets.

Geman, H., El-Karoui, N. \& Rochet, J.-C. (1995), 'Changes of numeraire, changes of probability measure and option pricing', Journal of Applied Probability 32 pp. 443-458.

Geske, R. (1977), 'The valuation of corporate securities as compound options', Journal of Financial and Quantitative Analysis pp. 541-552.

Huang, J.-Z. \& Huang, M. (2002), 'How much of the corporate-treasury yield spread is due to credit risk? a new calibration approach', Working paper Pennsylvania State University .

Hull, J. (2000), Options, Futures and Other Derivatives, Prentice Hall.

Janosi, T., Jarrow, R. \& Yildirim, Y. (2001), 'Estimating expected losses and liquidity discounts implicit in debt prices', Working Paper Cornell .

Jarrow, R. A. \& Turnbull, S. M. (1995), 'Pricing derivatives on financial securities subject to credit risk', Journal of Finance 50, 53-85.

Jarrow, R., Lando, D. \& Turnbull, S. (1997), 'A markov model for the term structure of credit spreads', Review of Financial Studies 10 (2), 481-523.

Jones, E., Mason, S. \& Rosenfeld, E. (1984), 'Contingent claims analysis of corporate capital structures: An empirical investigation', Journal of Finance 39, 611-627.

Kim, I., Ramaswamy, K. \& Sundaresan, S. (1993), 'Does default risk in coupons affect the valuation of corporate bonds?: A contingent claims model', Financial Management, Special Issue on Financial Distress .

Lando, D. (1997), Modeling Bonds and Derivatives with Default Risk, Cambridge University Press, pp. 369-393. 
Lando, D. (1998), 'On cox processes and credit risky securities', Review of Derivatives Research 2, 99-120.

Leland, H. (1994), 'Risky debt, bond covenants and optimal capital structure', The Journal of Finance 49. pp. 1213-1252.

Leland, H. E. (1998), 'Agency costs, risk management, and capital structure', Journal of Finance $\mathbf{5 3}$.

Leland, H. \& Toft, K. B. (1996), 'Optimal capital structure, endogenous bankruptcy and the term structure of credit spreads', Journal of Finance No. 3 Vol. 51 pp. 987-1019.

Liu, J., Longstaff, F. \& Mandell, R. (2002), 'The market price of credit risk: and empirical analysis of interest rate swap spreads', Working Paper $U C L A$.

Longstaff, F. A. \& Schwartz, E. S. (1995), 'A simple approach to valuing risky fixed and floating rate debt', The Journal of Finance 50, 789-819.

Mella-Barral, P. (1999), 'The dynamics of default and debt reorganization', Review of Financial Studies 12, 535-578.

Mella-Barral, P. \& Perraudin, W. (1997), 'Strategic debt service', Journal of Finance 52, 531-556.

Merton, R. C. (1974), 'On the pricing of corporate debt: The risk structure of interest rates', Journal of Finance 29, 449-4790.

Merton, R. C. (1990), Continuous-Time Finance, Blackwell Publishers.

Moody's Investors Service, G. C. R. (2001), 'Default and recovery rates of corporate bond issuers: 2000', February.

Moody's Investors Service, G. C. R. (2002), 'Default and recovery rates of corporate bond issuers: A statistical review of moody's ratings performance 1970-2001', February.

Newman, Y. S. \& Rierson, M. A. (2002), 'How downward-sloping are demand curves for corporate bonds', working paper Stanford University .

Nielsen, L. T., Saa-Requejo, J. \& Santa-Clara, P. (1993), 'Default risk and interest rate risk: The term structure of default spreads', Working paper INSEAD . 
Ogden, J. P. (1987), 'Determinants of the ratings and yields on corporate bonds: Tests of contingent claims model', The Journal of Financial Research $\mathbf{1 0 .}$

Perraudin, W. \& Taylor, A. (2002), 'Liquidity and the determinants of bond market spreads', working paper Birkbeck College .

Reilly, F. K. \& Wright, D. J. (1994), 'An analysis of High-Yield bond benchmarks', The Journal of Fixed Income pp. 6-25.

Reneby, J. (1998), Pricing Corporate Debt, PhD thesis, Stockholm School of Economics.

Ronn, E. I. \& Verma, A. K. (1986), 'Pricing Risk-Adjusted deposit insurance: An Option-Based model', Journal of Finance 41, 871-895.

Saá-Requejo, J. \& Santa-Clara, P. (1997), 'Bond pricing with default risk', Working paper.

Saunders, A. \& Allen, L. (2002), Credit Risk Measurement: New Approaches to Value at Risk and Other Paradigms, Wiley.

Wei, D. G. \& Guo, D. (1997), 'Pricing risky debt: An empirical comparison of the longstaff and schwartz and merton models', Journal of Fixed Income 7.

White, H. (1980), 'A heteroskedasticity-consistent covariance matrix estimator and a direct test of heteroskedasticity', Econometrica 48, 817-38.

Yu, F. (2002), 'Modeling expected return on defaultable bonds', Working Paper University of California, Irvine. 


\section{A Preliminaries}

- $Q^{B}$ is the probability measure under which price processes normalized with the money market account are martingales (the standard pricing measure)

- $Q^{G}$ is the measure under which price processes normalized with a dollar-in-default claim, $G\left(\omega_{t}, t\right)$, are martingales.

Define the default process

$$
X_{t} \equiv \frac{1}{\sigma} \ln \frac{\omega_{t}}{L_{t}}
$$

Default is defined through $X_{\mathcal{T}} \equiv 0$. The dynamics of the default process are

$$
d X=\mu^{m} d t+d W^{m}
$$

where $W^{m}$ is a Wiener-process under probability measure $Q^{m}$ and $\mu^{m}$ is its appurtenant drift, as given in Lemma :

$$
\begin{aligned}
\mu^{B} & =\frac{r-\beta-\alpha-0.5 \sigma^{2}}{\sigma} \\
\mu^{G} & =-\sqrt{\left(\mu^{B}\right)^{2}+2 r}
\end{aligned}
$$

The first passage time density at 0 for process the $X_{t}$ under probability measure $Q^{m}$ is

$$
f^{m}\left(X_{t} ; s\right)=\frac{X_{t}}{\sqrt{2 \pi(s-t)^{3}}} e^{-\frac{1}{2}\left(\frac{X_{t}+\mu^{m} \cdot(s-t)}{\sqrt{s-t}}\right)^{2}}
$$

Remark 1 Integrating the density function. It is holds that

$$
\int_{t}^{\infty} e^{-\rho(s-t)} f^{m}\left(X_{t} ; s\right) d s=e^{-X_{t}\left(\sqrt{\left(\mu^{m}\right)^{2}+2 \rho}+\mu^{m}\right)}
$$

provided $\left(\mu^{m}\right)^{2}+2 \rho \geq 0$.

Remark 2 Numeraires and change of probability measures. Loosely speaking it holds that, for a general measure $Q^{j}$,

$$
E^{j}[Y \cdot m]=E^{m}[Y] \cdot E^{j}[m]
$$


where $E^{m}$ is the expected value under the probability measure $Q^{m}$ defined through

$$
\left\{\begin{array}{c}
d Q^{m}=R^{j \rightarrow m} d Q^{j} \\
R^{j \rightarrow m}=\frac{m}{E^{j}[m]}
\end{array}\right.
$$

and $R^{j \rightarrow m}$ is the Radon-Nikodym derivative to take us from measure $j$ to m. See e.g. Geman et al. (1995).

\section{B Pricing formulae}

\section{B.1 Value of debt}

The pricing formula for debt issued at $t$ with principal $n=\alpha \cdot N_{t} \cdot d t$ is standard:

$$
d\left(\omega_{t}, t\right)=n \cdot\left(1-G\left(\omega_{t}, t\right)\right)+\delta \cdot n \cdot G\left(\omega_{t}, t\right)
$$

with the recovery rate determined as

$$
\delta=(1-\varepsilon-k) \cdot \frac{L_{t}}{N_{t}}
$$

\section{B.2 Lemmas 1 and 2}

By definition it holds that

$$
E^{B}\left[e^{-\rho(\mathcal{T}-t)}\right]=\int_{t}^{\infty} e^{-\rho(s-t)} f^{B}\left(X_{t} ; s\right) d s
$$

Applying Remark 1 this is equal to

$$
\int_{t}^{\infty} e^{-\rho(s-t)} f^{B}\left(X_{t} ; s\right) d s=e^{-X_{t}\left(\sqrt{\left(\mu^{B}\right)^{2}+2 \rho}+\mu^{B}\right)}
$$

and the lemmas follow immediately.

\section{B.3 Proposition 1}

Inserting (3) into (2) we obtain 


$$
\mathcal{E}\left(\omega_{t}, t\right) \equiv\left\{\begin{array}{c}
E^{B}\left[\int_{t}^{\infty} e^{-r(s-t)} \beta \omega_{s} I_{\mathcal{T} \nless s} d s\right] \\
-E^{B}\left[\int_{t}^{\infty} e^{-r(s-t)}(1-\tau) C_{s} I_{\mathcal{T} \nless s} d s\right] \\
+E^{B}\left[\int_{t}^{\infty} e^{-r(s-t)} d\left(\omega_{s}, s\right) I_{\mathcal{T} \nless s} d s\right] \\
+E^{B}\left[e^{-r(\mathcal{T}-t)} \varepsilon_{\mathcal{T}} L_{\mathcal{T}}\right]
\end{array}\right.
$$

Consider first line 1:

$$
\begin{aligned}
& E^{B}\left[\int_{t}^{\infty} e^{-r(s-t)} \beta \omega_{s}\left(1-I_{\mathcal{T}<s}\right) d s\right] \\
= & E^{B}\left[\int_{t}^{\infty} e^{-r(s-t)} \beta \omega_{s} d s\right] \cdot-E^{B}\left[\int_{t}^{\infty} e^{-r(s-t)} \beta \omega_{s} I_{\mathcal{T}<s} d s\right] \\
= & \omega_{t}-\underbrace{E^{B}\left[\int_{\mathcal{T}}^{\infty} e^{-r(s-t)} \beta \omega_{s} d s\right]}_{\text {value at } t \text { of earnings after default }}=\omega_{t}-E^{B}\left[e^{-r(\mathcal{T}-t)} \omega_{\mathcal{T}}\right] \\
= & \omega_{t}-E^{B}\left[e^{-r(\mathcal{T}-t)} L_{\mathcal{T}}\right]=\omega_{t}-E^{B}\left[e^{-r(\mathcal{T}-t)} L_{t} e^{\alpha(\mathcal{T}-t)}\right]
\end{aligned}
$$

Now split the coupon stream (line two of eq. (8)) into two parts: debt service to current debtholders and debt service to future debtholders.

$$
\begin{aligned}
& \int_{t}^{\infty} e^{-r(s-t)}(1-\tau) C_{s} I_{\mathcal{T} \nless s} d s \\
= & \int_{t}^{\infty} e^{-r(s-t)}(1-\tau) C_{t} I_{\mathcal{T} \nless s} d s \\
& +\int_{t}^{\infty} e^{-r(s-t)}(1-\tau) C_{t}\left(e^{\alpha(s-t)}-1\right) I_{\mathcal{T} \nless s} d s
\end{aligned}
$$

(The coupon accruing to debt issued after time $t$, at time $s$, is $C_{s}-C_{t}=$ $C_{t} e^{\alpha(s-t)}-C_{t}$.) The value of future borrowed money (line three of eq. (8)) must be equal to the value of total debt service to future borrowed money plus the value of payouts in default accruing to future borrowers. Formally

$$
\begin{aligned}
& E^{B}\left[\int_{t}^{\infty} e^{-r(s-t)} d\left(\omega_{s}, s\right) I_{\mathcal{T} \nless s} d s\right] \\
= & E^{B}\left[\int_{t}^{\infty} e^{-r(s-t)} C_{t}\left(e^{\alpha(s-t)}-1\right) I_{\mathcal{T} \nless s} d s\right] \\
& +(1-\varepsilon-k) \cdot E^{B}\left[e^{-r(\mathcal{T}-t)}\left(L_{\mathcal{T}}-L_{t}\right)\right]
\end{aligned}
$$


Applying (9), (10) and (11) to (8) and cancelling terms, we arrive at

$$
\begin{aligned}
\mathcal{E}\left(\omega_{t}, t\right)= & \omega_{t}-L_{t} \cdot E^{B}\left[e^{(\alpha-r)(\mathcal{T}-t)}\right] \\
& -C_{t} \cdot E^{B}\left[\int_{t}^{\infty} e^{-r(s-t)} I_{\mathcal{T} \nless s} d s\right] \\
& +\tau C_{t} \cdot E^{B}\left[\int_{t}^{\infty} e^{-(r-\alpha)(s-t)} I_{\mathcal{T} \nless s} d s\right] \\
& +(1-\varepsilon-k) L_{t} \cdot E^{B}\left[e^{-(r-\alpha)(\mathcal{T}-t)}-e^{-r(\mathcal{T}-t)}\right] \\
& +\varepsilon L_{t} \cdot E^{B}\left[e^{-(r-\alpha)(\mathcal{T}-t)}\right]
\end{aligned}
$$

The proposition, for $r \neq \alpha$, follows using Remark 1. The result for $r=\alpha$ is obtained from taking the limit as $\alpha \rightarrow r$.

\section{B.4 Lemma 5}

The value of receiving a dollar if default occurs prior to $T$ must be equal to receiving a dollar-in-default claim with infinite maturity, less a claim where you receive a dollar in default conditional on it not occurring prior to $T$. Formally

$$
G\left(\omega_{t}, t \mid \mathcal{T}<T\right)=G\left(\omega_{t}, t\right)-e^{-r(T-t)} E^{B}\left[G\left(\omega_{T}, T\right) \cdot I_{\mathcal{T} \nless T}\right]
$$

Using the $Q^{G}$-measure, we can separate the variables (cf. Remark 2 above) within the expectation brackets.

$$
\begin{aligned}
G\left(\omega_{t}, t \mid \mathcal{T}<T\right) & =G\left(\omega_{t}, t\right)-e^{-r(T-t)} E^{B}\left[G\left(\omega_{T}, T\right)\right] \cdot E^{G}\left[I_{\mathcal{T} \nless T}\right] \\
& =G\left(\omega_{t}, t\right) \cdot\left(1-Q^{G}(\mathcal{T} \not \leq T)\right)
\end{aligned}
$$

\section{B.5 The default threshold}

The endogenous reorganization barrier is the value of assets at which the value of equity in solvency equals the value of equity in reorganization.

$$
\mathcal{E}\left(\omega_{t}, t\right)=\varepsilon \cdot L_{t}
$$

Applying a smooth pasting condition implies that

$$
\left.\frac{\partial \mathcal{E}\left(\omega_{t}, t\right)}{\partial \omega_{t}}\right|_{\omega_{t}=L_{t}}=\varepsilon
$$


The optimal barrier can be solved for in closed form. When $\beta>0$ and $r \neq \alpha$, it is

$$
\left.L_{t}\right|_{\beta>0, r \neq \alpha}=\frac{\tau \frac{r}{r-\alpha} \theta^{\alpha}-\theta}{(\varepsilon-1) \cdot\left(1+\theta^{\alpha}\right)+(1-\varepsilon-k) \cdot\left(\theta^{\alpha}-\theta\right)} N_{t}
$$

As can be seen, the endogenous barrier grows at rate $\alpha$. 
TABle 1: DESCRIPTIVE STATISTICS OF BOND ISSUES AND ISSUERS.

Based on 141 bonds (firms) during the period January 1994 to February 1998.

\begin{tabular}{|c|c|c|c|c|c|c|c|c|c|c|}
\hline Sample & $\begin{array}{l}\text { Market } \\
\text { spread }\end{array}$ & $\begin{array}{l}\text { Market } \\
\text { price }\end{array}$ & Coupon & $\begin{array}{l}\text { S\&P } \\
\text { rating }\end{array}$ & $\begin{array}{l}\text { Issue } \\
\text { size }\end{array}$ & $\begin{array}{l}\text { Issue } \\
\text { age }\end{array}$ & Maturity & Leverage & $\begin{array}{l}\text { Firm } \\
\text { size }\end{array}$ & $\begin{array}{c}\text { Stock } \\
\text { volatility }\end{array}$ \\
\hline All $(n=5594)$ & 89 & 106.64 & 8.09 & 8.0 & 191,431 & 3.8 & 11.8 & $41.1 \%$ & 17,725 & $27.9 \%$ \\
\hline Std. dev. & 82 & 9.90 & 1.27 & 2.8 & 117,588 & 2.4 & 7.4 & $17.9 \%$ & 29,412 & $10.5 \%$ \\
\hline High rating $(n=2270)$ & 58 & 108.30 & 7.89 & 5.7 & 203,263 & 4.3 & 12.6 & $30.6 \%$ & 25,155 & $24.1 \%$ \\
\hline Std. dev. & 21 & 10.71 & $1.4^{2}$ & 1.5 & 126,912 & 2.6 & 7.5 & $12.1 \%$ & 28,638 & $6.3 \%$ \\
\hline Low Rating $(n=3324)$ & 109 & 105.50 & 8.22 & 9.6 & 183,337 & 3.4 & 11.2 & $48.3 \%$ & 12,641 & $30.5 \%$ \\
\hline Std. dev. & 100 & 9.13 & 1.14 & 2.2 & 110,046 & 2.1 & 7.3 & $17.7 \%$ & 28,852 & $12.0 \%$ \\
\hline Speculative Grade $(n=588)$ & 229 & 103.06 & 8.89 & 12.9 & 189,949 & 2.9 & 9.0 & $61.6 \%$ & 10,048 & $40.5 \%$ \\
\hline Std. dev. & 189 & 10.94 & 1.32 & 2.8 & 91,000 & 1.9 & 5.8 & $19.4 \%$ & 8,987 & $16.4 \%$ \\
\hline Long Maturity $(n=2577)$ & 92 & 109.79 & 8.39 & 7.6 & 196,602 & 4.4 & 17.9 & $42.2 \%$ & 23,265 & $27.0 \%$ \\
\hline Std. dev. & 60 & 11.33 & 1.12 & 2.5 & 129,876 & 2.7 & 6.8 & $18.0 \%$ & 37,960 & $10.5 \%$ \\
\hline \multirow[t]{2}{*}{ Short Maturity $(n=3017)$} & 86 & 103.95 & 7.83 & 8.4 & 187,024 & 3.2 & 6.6 & $40.2 \%$ & 13,002 & $28.7 \%$ \\
\hline & 97 & 7.52 & 1.32 & 2.9 & 105,816 & 1.9 & 1.9 & $17.8 \%$ & 18,055 & $10.5 \%$ \\
\hline
\end{tabular}




\section{TABle 2: PARAMETER ESTIMATES}

Based on estimation with bond price information. Cross-sectional averages are displayed. The distance to default is defined as firm value divided by default threshold. Sample size: 5452 .

\begin{tabular}{lrrrrrr}
\hline \hline \multirow{2}{*}{ Sample } & $\begin{array}{c}\text { Debt } \\
\text { increase }\end{array}$ & $\begin{array}{c}\text { Free } \\
\text { cash } \\
\text { flow }\end{array}$ & $\begin{array}{c}\text { Asset } \\
\text { volatility }\end{array}$ & $\begin{array}{c}\text { Default } \\
\text { threshold }\end{array}$ & $\begin{array}{c}\text { Firm } \\
\text { value }\end{array}$ & $\begin{array}{c}\text { Distance } \\
\text { to default }\end{array}$ \\
\hline \multirow{2}{*}{ All } & $8.3 \%$ & $1.2 \%$ & $26.4 \%$ & 4,138 & 16,926 & 3.16 \\
& $5.4 \%$ & $1.3 \%$ & $12.3 \%$ & 13,926 & 28,472 & 0.86 \\
High rating & $11.0 \%$ & $0.8 \%$ & $27.4 \%$ & 3,865 & 26,220 & 3.38 \\
& $5.9 \%$ & $1.0 \%$ & $10.9 \%$ & 5,879 & 32,181 & 0.98 \\
Low Rating & & & & & & \\
& $6.5 \%$ & $1.5 \%$ & $25.8 \%$ & 4,325 & 10,561 & 3.00 \\
& $4.0 \%$ & $1.4 \%$ & $13.2 \%$ & 17,408 & 23,605 & 0.73 \\
Speculative Grade & $5.3 \%$ & $1.5 \%$ & $27.3 \%$ & 2,581 & 7,976 & 2.47 \\
& $2.1 \%$ & $1.7 \%$ & $15.8 \%$ & 2,537 & 7,849 & 0.65 \\
& & & & & & \\
\hline \hline
\end{tabular}


TABle 3: One month out-OF-SAmple Performance. No Bond info.

RPE denotes the Relative Pricing Error and RMSE the Root Mean Squared Error in Relative Prices (RP). RSE is the Relative Spread Error, and SE the Spread Error. Absolute values are enclosed in | |.Corr(RP)/(corr(S) denote the correlation between estimated and actual Relative Prices and Spreads, respectively. Sample size: 5594 .

\begin{tabular}{|c|c|c|c|c|c|c|c|c|c|c|}
\hline & & \multicolumn{4}{|c|}{ Prices } & \multicolumn{5}{|c|}{ Spreads } \\
\hline & & $\mathrm{RPE}$ & $|\mathrm{RPE}|$ & $\mathrm{RMSE}(\mathrm{RP})$ & $\operatorname{Corr}(\mathrm{RP})$ & RSE & $|\mathrm{RSE}|$ & SE & $|\mathrm{SE}|$ & $\operatorname{Corr}(\mathrm{S})$ \\
\hline \multirow[t]{2}{*}{ All bonds } & Mean & $4.3 \%$ & $5.0 \%$ & $6.4 \%$ & $87 \%$ & $-71 \%$ & $85 \%$ & -58 & 70 & $28 \%$ \\
\hline & Std. dev. & $4.8 \%$ & $4.0 \%$ & & $22 \%$ & $63 \%$ & $42 \%$ & 73 & 61 & $41 \%$ \\
\hline \multirow[t]{2}{*}{ High Rating } & Mean & $3.8 \%$ & $4.1 \%$ & $5.0 \%$ & $94 \%$ & $-84 \%$ & $91 \%$ & -48 & 52 & $24 \%$ \\
\hline & Std. dev. & $3.2 \%$ & $2.9 \%$ & & $15 \%$ & $45 \%$ & $28 \%$ & 30 & 23 & $38 \%$ \\
\hline \multirow[t]{2}{*}{ Low Rating } & Mean & $4.8 \%$ & $5.6 \%$ & $7.1 \%$ & $84 \%$ & $-66 \%$ & $80 \%$ & -69 & 81 & $31 \%$ \\
\hline & Std. dev. & $5.3 \%$ & $4.4 \%$ & & $22 \%$ & $61 \%$ & $42 \%$ & 82 & 70 & $42 \%$ \\
\hline \multirow[t]{2}{*}{ Speculative Grade } & Mean & $7.7 \%$ & $8.8 \%$ & $11.3 \%$ & $74 \%$ & $-63 \%$ & $70 \%$ & -133 & 152 & $36 \%$ \\
\hline & Std. dev. & $8.2 \%$ & $7.0 \%$ & & $17 \%$ & $42 \%$ & $28 \%$ & 144 & 124 & $39 \%$ \\
\hline
\end{tabular}


Table 4: One month out-of-SAmple Performance. Bond info.

RPE denotes the Relative Pricing Error and RMSE the Root Mean Squared Error in Relative Prices (RP). RSE is the Relative Spread Error, and SE the Spread Error. Absolute values are enclosed in | |. Corr (RP)/(corr(S) denote the correlation between estimated and actual Relative Prices and Spreads, respectively. Sample size: 5452 .

\begin{tabular}{|c|c|c|c|c|c|c|c|c|c|c|}
\hline & & \multicolumn{4}{|c|}{ Prices } & \multicolumn{5}{|c|}{ Spreads } \\
\hline & & $\mathrm{RPE}$ & $|\mathrm{RPE}|$ & RMSE(RP) & Corr (RP) & RSE & $|\mathrm{RSE}|$ & SE & $|\mathrm{SE}|$ & $\operatorname{Corr}(\mathrm{S})$ \\
\hline \multirow[t]{2}{*}{ All bonds } & Mean & $0.1 \%$ & $0.7 \%$ & $1.2 \%$ & $96 \%$ & $-2 \%$ & $13 \%$ & -2 & 11 & $61 \%$ \\
\hline & Std. dev. & $1.2 \%$ & $0.9 \%$ & & $6 \%$ & $18 \%$ & $12 \%$ & 19 & 15 & $24 \%$ \\
\hline \multirow[t]{2}{*}{ High Rating } & Mean & $0.1 \%$ & $0.5 \%$ & $0.7 \%$ & $98 \%$ & $-3 \%$ & $12 \%$ & -2 & 7 & $61 \%$ \\
\hline & Std. dev. & $0.7 \%$ & $0.5 \%$ & & $4 \%$ & $17 \%$ & $12 \%$ & 9 & 6 & $18 \%$ \\
\hline \multirow[t]{2}{*}{ Low Rating } & Mean & $0.1 \%$ & $0.9 \%$ & $1.4 \%$ & $95 \%$ & $-1 \%$ & $14 \%$ & -2 & 14 & $62 \%$ \\
\hline & Std. dev. & $1.4 \%$ & $1.1 \%$ & & $7 \%$ & $18 \%$ & $13 \%$ & 23 & 19 & $27 \%$ \\
\hline \multirow[t]{2}{*}{ Speculative Grade } & Mean & $0.2 \%$ & $1.6 \%$ & $2.4 \%$ & $90 \%$ & $-1 \%$ & $14 \%$ & -4 & 30 & $76 \%$ \\
\hline & Std. dev. & $2.4 \%$ & $1.8 \%$ & & $10 \%$ & $18 \%$ & $12 \%$ & 45 & 34 & $18 \%$ \\
\hline
\end{tabular}


Table 5: Multiple months out-of-Sample Performance. Bond info.

RPE denotes the Relative Pricing Error and RMSE the Root Mean Squared Error in Relative Prices (RP). RSE is the Relative Spread Error, and SE the Spread Error. Absolute values are enclosed in | |. Corr(RP)/Corr(S) denote the correlation between estimated and actual Relative Prices and Spreads, respectively. Sample size: 5452 .

\begin{tabular}{|c|c|c|c|c|c|c|c|c|c|c|}
\hline & & \multicolumn{4}{|c|}{ Prices } & \multicolumn{5}{|c|}{ Spreads } \\
\hline & & $\mathrm{RPE}$ & $|\mathrm{RPE}|$ & RMSE(RP) & Corr(RP) & RSE & $|\mathrm{RSE}|$ & SE & $|\mathrm{SE}|$ & $\operatorname{Corr}(\mathrm{S})$ \\
\hline All bonds & $\begin{array}{r}\text { Mean } \\
\text { Std. dev. }\end{array}$ & $\begin{array}{l}0.9 \% \\
3.7 \%\end{array}$ & $\begin{array}{l}2.6 \% \\
2.8 \%\end{array}$ & $3.8 \%$ & $\begin{array}{l}89 \% \\
18 \%\end{array}$ & $\begin{array}{r}-18 \% \\
58 \%\end{array}$ & $\begin{array}{l}47 \% \\
38 \%\end{array}$ & $\begin{array}{r}-13 \\
56\end{array}$ & $\begin{array}{l}38 \\
43\end{array}$ & $\begin{array}{l}34 \% \\
46 \%\end{array}$ \\
\hline High Rating & $\begin{array}{r}\text { Mean } \\
\text { Std. dev. }\end{array}$ & $\begin{array}{l}0.7 \% \\
2.6 \%\end{array}$ & $\begin{array}{l}2.0 \% \\
1.8 \%\end{array}$ & $2.7 \%$ & $\begin{array}{l}95 \% \\
15 \%\end{array}$ & $\begin{array}{r}-25 \% \\
56 \%\end{array}$ & $\begin{array}{l}49 \% \\
36 \%\end{array}$ & $\begin{array}{r}-11 \\
32\end{array}$ & $\begin{array}{l}26 \\
21\end{array}$ & $\begin{array}{l}28 \% \\
48 \%\end{array}$ \\
\hline Low Rating & $\begin{array}{r}\text { Mean } \\
\text { Std. dev. }\end{array}$ & $\begin{array}{l}0.9 \% \\
4.3 \%\end{array}$ & $\begin{array}{l}3.0 \% \\
3.2 \%\end{array}$ & $4.4 \%$ & $\begin{array}{l}86 \% \\
20 \%\end{array}$ & $\begin{array}{r}-13 \% \\
59 \%\end{array}$ & $\begin{array}{l}46 \% \\
40 \%\end{array}$ & $\begin{array}{r}-15 \\
68\end{array}$ & $\begin{array}{l}46 \\
52\end{array}$ & $\begin{array}{l}38 \% \\
44 \%\end{array}$ \\
\hline Speculative Grade & $\begin{array}{r}\text { Mean } \\
\text { Std. dev }\end{array}$ & $\begin{array}{l}2.0 \% \\
6.0 \%\end{array}$ & $\begin{array}{l}4.6 \% \\
4.3 \%\end{array}$ & $6.3 \%$ & $\begin{array}{l}78 \% \\
19 \%\end{array}$ & $\begin{array}{r}-17 \% \\
47 \%\end{array}$ & $\begin{array}{l}41 \% \\
27 \%\end{array}$ & $\begin{array}{l}-38 \\
120\end{array}$ & $\begin{array}{l}89 \\
88\end{array}$ & $\begin{array}{l}57 \% \\
34 \%\end{array}$ \\
\hline
\end{tabular}


Table 6: One month out-Of-SAmple Performance in Changes. Bond info.

Panel A: Basic Results

PCE denotes the Price Change Error and RMSE the Root Mean Squared Error in price changes (PC).SCE is the Spread Change Error. Absolute values are enclosed in $\mid$. Corr $(\mathrm{PC})(\operatorname{corr}(\mathrm{SC})$ denote the correlation between estimated and actual Price Changes and Spread Changes, respectively. Sample size: 5452 .

\begin{tabular}{|c|c|c|c|c|c|c|c|c|}
\hline & & \multicolumn{2}{|r|}{ Price } & \multicolumn{2}{|l|}{ changes } & \multicolumn{2}{|r|}{ Spread } & changes \\
\hline & & PCE & $|\mathrm{PCE}|$ & RMSE(PC) & Corr(PC) & $\mathrm{SCE}$ & $|\mathrm{SCE}|$ & Corr(SC) \\
\hline \multirow[t]{2}{*}{ All bonds } & Mean & 0.10 & 0.78 & 1.21 & $91 \%$ & -2 & 11 & $13 \%$ \\
\hline & Std. dev. & 1.20 & 0.93 & & $11 \%$ & 19 & 15 & $23 \%$ \\
\hline \multirow[t]{2}{*}{ High Rating } & Mean & 0.10 & 0.54 & 0.79 & $96 \%$ & -2 & 7 & $13 \%$ \\
\hline & Std. dev. & 0.78 & 0.57 & & $3 \%$ & 9 & 6 & $17 \%$ \\
\hline \multirow[t]{2}{*}{ Low Rating } & Mean & 0.10 & 0.93 & 1.43 & $88 \%$ & -2 & 14 & $13 \%$ \\
\hline & Std. dev. & 1.42 & 1.08 & & $12 \%$ & 23 & 19 & $26 \%$ \\
\hline \multirow[t]{2}{*}{ Speculative Grade } & Mean & 0.17 & 1.56 & 2.21 & $74 \%$ & -4 & 30 & $22 \%$ \\
\hline & Std. dev. & 2.21 & 1.57 & & $19 \%$ & 45 & 34 & $24 \%$ \\
\hline
\end{tabular}


Table 6: One month out-Of-Sample Performance in Changes. Bond info.

PANEL B: SMALL AND LARGE SPREAD CHANGES

Based on pooled estimation of the following regression equation $S C_{i, t}^{\text {market }}=a_{i}+b \cdot S C_{i, t}^{\text {model }}+\varepsilon_{i, t}$. White $(1980)$ heteroskedasticity consistent covariance matrix estimator. Sample size: 5452

\begin{tabular}{rrrrr}
\hline \hline & All changes & Smaller than 15 bps & Larger than 15 bps & Larger than 30 bps \\
\cline { 3 - 5 }$\beta$ & 0.28 & 0.05 & 0.72 & 0.94 \\
t-stat & 5.16 & 7.03 & 5.71 & 5.90 \\
Adjusted $R^{2}$ & $6.30 \%$ & $1.10 \%$ & $5.50 \%$ & $12.80 \%$ \\
\hline \hline
\end{tabular}


TAble 7: Interest Rate Sensitivities of MOdel AND MARKet SPREAdS.

Based on pooled estimation of the following regression equation $S C_{i, t}=a_{i}+b \cdot[\text { level }]_{i, t}+c \cdot[\text { slope }]_{i, t}+\varepsilon_{i, t} .[?]$ heteroskedasticity consistent covariance matrix estimator. Sample size: 5452

\begin{tabular}{|c|c|c|c|c|c|}
\hline \multirow[t]{2}{*}{ Dependent } & \multirow[t]{2}{*}{ variable: } & \multicolumn{2}{|c|}{ Market spread changes } & \multicolumn{2}{|c|}{ Model spread changes } \\
\hline & & Coefficient & t-stat & Coefficient & t-stat \\
\hline \multirow[t]{2}{*}{ All } & Level & -0.02 & -1.00 & -0.01 & -0.64 \\
\hline & Slope & -0.03 & $-2.80^{*}$ & -0.01 & -0.91 \\
\hline \multirow[t]{2}{*}{ High Rating } & & -0.02 & -2.38 & -0.03 & -3.32 \\
\hline & & -0.02 & $-3.91^{*}$ & -0.02 & $-2.51^{*}$ \\
\hline \multirow[t]{2}{*}{ Low Rating } & & -0.01 & -0.47 & 0.01 & 0.39 \\
\hline & & -0.04 & $-2.10^{*}$ & -0.01 & -0.27 \\
\hline \multirow{2}{*}{ Speculative } & & 0.12 & 0.93 & 0.03 & 0.27 \\
\hline & & -0.10 & -1.17 & 0.12 & 1.61 \\
\hline \multirow[t]{2}{*}{ Long } & & -0.04 & -3.06 & -0.06 & -3.03 \\
\hline & & -0.05 & $-4.39^{*}$ & -0.06 & $-3.15^{*}$ \\
\hline \multirow[t]{2}{*}{ Short } & & 0.01 & 0.38 & 0.04 & 1.86 \\
\hline & & -0.01 & -0.75 & 0.03 & 1.49 \\
\hline
\end{tabular}


TABLE 8: EXPLANATORY VARIABLES FOR ERROR ANALYSIS REGRESSIONS

\begin{tabular}{ll}
\hline \hline Bond specific & \\
\hline Rating & Numerical S\&P rating (AAA=1, D=23). \\
$\begin{array}{l}\text { On-the-run } \\
\text { Maturity }\end{array}$ & Dummy: 1 if age $<3$ months, 0 otherwise \\
Issue size & Maturity date] - [Quote date] (years) \\
Coupon & Dollar size of issue (amount outstanding) \\
& \\
Firm specific & Bearly coupon in dollar \\
\hline Leverage & MV of equity + BV of debt \\
Firm size & MV of equity + BV of debt \\
Historical stock return & During month preceeding pricing date \\
Historical stock volatility & During 250 days preceeding pricing date. \\
& \\
Economy wide & \\
\hline Liquidity premium in & Spread between on-the-run and off-the-run \\
Treasury market & Treasury issues (2, 5, 10 and 30 years to maturity) \\
Money zero maturity & Measure of liquidity provision by Federal Reserve \\
Issuance & Monthly dollar value of new corporate bond issues in the US \\
activity & Return on S\&P 500 index \\
Market Return & VIX: CBOE implied volatility index \\
Market Volatility & Moody's AAA - Aaa yield index \\
Default Premium & 10 year Treasury yield \\
Level of term structure & 10 year - 2 year Treasury yields \\
Slope of term strucure & \\
\hline \hline
\end{tabular}


TABLE 9: ERROR ANALYSIS - YIELD SPREAD LEVELS.

The results are based on pooled OLS-regressions with White standard errors and random effects intercepts. The dependent variable is the spread error, SE, from pricing without bond information. The explanatory variables are defined in table 8 . An asterisk denotes $5 \%$ significance.

\begin{tabular}{|c|c|c|c|c|c|c|c|c|c|c|c|}
\hline & \multirow[b]{2}{*}{ Constant } & & \multicolumn{2}{|r|}{ Bond } & specific & \multicolumn{2}{|l|}{ variables } & \multirow{2}{*}{$\begin{array}{r}\text { Firm } \\
\text { Leverage }\end{array}$} & \multirow{2}{*}{$\begin{array}{r}\text { specific } \\
\text { Firm } \\
\text { size }\end{array}$} & \multicolumn{2}{|l|}{ variables } \\
\hline & & & Rating & On-the-run & Maturity & $\begin{array}{r}\text { Issue } \\
\text { size }\end{array}$ & Coupon & & & $\begin{array}{l}\text { Historical } \\
\text { stock ret. }\end{array}$ & $\begin{array}{l}\text { Historical } \\
\text { stock vol. }\end{array}$ \\
\hline All & 17.45 & & -14.75 & 7.05 & -0.21 & 0.00 & -4.90 & 19.53 & 0.00 & -32.45 & 434.96 \\
\hline errors & 0.47 & & $-21.41^{*}$ & $2.19^{*}$ & -0.44 & 1.94 & -1.76 & $2.06^{*}$ & $-2.32^{*}$ & $-5.09^{*}$ & $51.05^{*}$ \\
\hline Negative & -8.18 & & -7.48 & 5.00 & -0.43 & 0.00 & -2.08 & -71.29 & 0.00 & -15.93 & 107.10 \\
\hline errors & -0.27 & & $-13.08^{*}$ & $1.97^{*}$ & -1.04 & $2.32^{*}$ & -0.85 & $-8.77^{*}$ & $-2.90^{*}$ & $-3.01^{*}$ & $10.47^{*}$ \\
\hline Positive & -146.42 & & -26.82 & 36.19 & -1.30 & 0.00 & -13.89 & 276.09 & 0.00 & -74.70 & 495.30 \\
\hline \multirow[t]{3}{*}{ errors } & -0.65 & & $-5.77^{*}$ & 1.72 & -0.54 & 0.62 & -0.63 & $7.09^{*}$ & -0.26 & $-4.47^{*}$ & $27.72^{*}$ \\
\hline & & & & & & Economy & wide & variables & & & \\
\hline & $\begin{array}{r}\text { Liquidity } \\
2 \mathrm{y} .\end{array}$ & $\begin{array}{r}\text { premium } \\
5 \mathrm{y} .\end{array}$ & $\begin{array}{r}\text { in Treasury } \\
10 \mathrm{y} .\end{array}$ & $\begin{array}{r}\text { market } \\
30 \mathrm{y} .\end{array}$ & $\begin{array}{r}\text { Money zero } \\
\text { maturity }\end{array}$ & $\begin{array}{r}\text { Issuance } \\
\text { activity }\end{array}$ & $\begin{array}{r}\text { Market } \\
\text { return }\end{array}$ & $\begin{array}{r}\text { Market } \\
\text { volatility }\end{array}$ & $\begin{array}{r}\text { Default } \\
\text { premium }\end{array}$ & $\begin{array}{l}\text { Term } \\
\text { Level }\end{array}$ & $\begin{array}{r}\text { structure } \\
\text { Slope }\end{array}$ \\
\hline All & -164.94 & -244.30 & -77.50 & -99.40 & -0.01 & 0.03 & 50.99 & 0.79 & 20.84 & -5.64 & -11.19 \\
\hline errors & $-3.10^{*}$ & $-3.05^{*}$ & $-2.55^{*}$ & $-3.18^{*}$ & -1.41 & 0.33 & $2.58^{*}$ & $2.79^{*}$ & 1.38 & $-3.51^{*}$ & $-3.54^{*}$ \\
\hline Negative & -121.87 & -136.15 & -58.03 & -96.48 & 0.01 & -0.01 & 29.61 & 0.57 & 23.64 & -3.05 & -7.94 \\
\hline errors & $-2.91^{*}$ & $-2.15^{*}$ & $-2.41^{*}$ & $-3.92^{*}$ & 1.02 & -0.10 & 1.88 & $2.51^{*}$ & $1.98^{*}$ & $-2.40^{*}$ & $-3.17^{*}$ \\
\hline Positive & -397.55 & -205.62 & 227.61 & 98.00 & 0.04 & 0.53 & -55.65 & -1.85 & -35.29 & 15.25 & 5.19 \\
\hline errors & -1.58 & -0.65 & 1.77 & 0.70 & 1.25 & 1.62 & -0.70 & -1.55 & -0.49 & $2.17^{*}$ & 0.36 \\
\hline
\end{tabular}


TABLE 10 ERROR ANALYSiS - YIELD SPREAD CHANGES

The results are based on pooled OLS-regressions with White standard errors and common intercept. The dependent variable is [one-month model spread change] - [one-month market spread change]. Model spreads are calulated using bond price information. The explanatory variables are the one-month changes in the variables defined in table 8. An asterisk denotes $5 \%$ significance.

\begin{tabular}{|c|c|c|c|c|c|c|c|c|c|c|c|}
\hline & & & & Bond & specific & variables & & Firm & specific & variables & \\
\hline & Constant & & Rating & On-the-run & Maturity & $\begin{array}{r}\text { Issue } \\
\text { size }\end{array}$ & Coupon & Leverage & $\begin{array}{r}\text { Firm } \\
\text { size }\end{array}$ & $\begin{array}{l}\text { Historical } \\
\text { stock ret. }\end{array}$ & $\begin{array}{l}\text { Historical } \\
\text { stock vol. }\end{array}$ \\
\hline All & 0.23 & & -2.64 & -2.56 & NA & NA & NA & 381.18 & 0.00 & -31.09 & 39.06 \\
\hline changes & 0.65 & & -1.64 & -0.80 & & & & $5.39^{*}$ & 0.89 & $-4.08^{*}$ & 1.86 \\
\hline Large & 7.57 & & -26.84 & -57.16 & NA & NA & NA & -208.51 & 0.00 & -113.51 & 79.11 \\
\hline changes & 0.74 & & -1.18 & -1.21 & & & & -0.45 & 0.12 & -1.82 & 1.21 \\
\hline \multirow{5}{*}{$\begin{array}{r}\text { Small } \\
\text { changes }\end{array}$} & -0.12 & & -0.35 & -0.87 & \multirow[t]{3}{*}{ NA } & NA & NA & 364.91 & 0.00 & -22.82 & 26.90 \\
\hline & -0.70 & & -0.84 & -0.86 & & & & $4.93^{*}$ & -0.65 & $-3.58^{*}$ & $2.45^{*}$ \\
\hline & & & & & & Economy & wide & variables & & & \\
\hline & \multicolumn{4}{|c|}{ Liquidity premium in Treasury market } & \multirow{2}{*}{$\begin{array}{r}\text { Money zero } \\
\text { maturity }\end{array}$} & \multirow{2}{*}{$\begin{array}{r}\text { Issuance } \\
\text { activity }\end{array}$} & \multirow{2}{*}{$\begin{array}{l}\text { Market } \\
\text { return }\end{array}$} & \multirow{2}{*}{$\begin{array}{r}\text { Market } \\
\text { volatility }\end{array}$} & \multirow{2}{*}{$\begin{array}{l}\text { Default } \\
\text { premium }\end{array}$} & \multirow{2}{*}{$\begin{array}{r}\text { Term structure } \\
\text { Level }\end{array}$} & \multirow[b]{2}{*}{ Slope } \\
\hline & $2 \mathrm{y}$ & $5 \mathrm{y}$ & $10 \mathrm{y}$ & $30 \mathrm{y}$ & & & & & & & \\
\hline All & -26.22 & -157.16 & -24.83 & -50.60 & -0.09 & 0.01 & -0.97 & -0.02 & -18.93 & 2.42 & 0.91 \\
\hline changes & -1.39 & $-5.66^{*}$ & $-2.42^{*}$ & $-3.87^{*}$ & $-4.61^{*}$ & 0.15 & -0.15 & -0.18 & -1.67 & $2.28^{*}$ & 0.41 \\
\hline Large & -812.02 & -486.87 & 170.86 & -359.95 & -0.47 & -0.72 & 2.14 & 2.14 & -36.00 & 36.30 & 126.02 \\
\hline changes & -1.23 & -0.69 & 0.60 & -0.84 & -1.00 & -0.91 & 0.01 & 0.69 & -0.11 & 1.46 & $2.00^{*}$ \\
\hline \multirow{2}{*}{$\begin{array}{r}\text { Small } \\
\text { changes }\end{array}$} & -8.02 & -94.92 & -17.82 & -38.34 & -0.06 & -0.02 & -6.94 & -0.09 & 1.39 & -0.02 & $-2.41^{*}$ \\
\hline & -1.02 & $-5.77^{*}$ & $-2.70^{*}$ & $-5.11^{*}$ & $-6.46^{*}$ & -1.06 & -1.95 & -1.58 & 0.25 & -0.04 & -2.18 \\
\hline
\end{tabular}


Figure 1: Estimated Asset volatility over time.

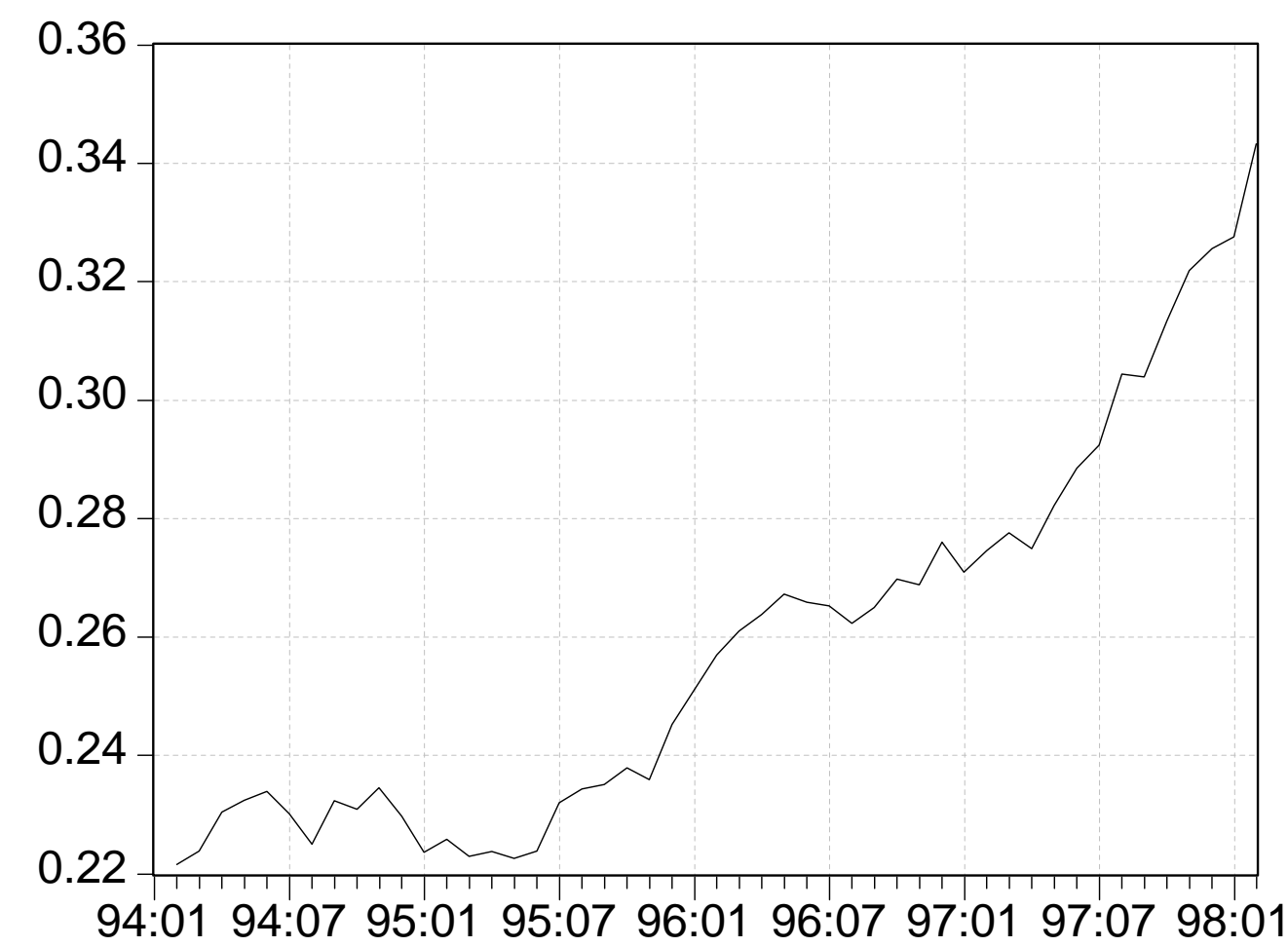


Figure 2: Multiple months out-of-Sample Performance. Some Examples.

The y-axis shows the spread in basis points. SPM (solid lines) denotes the market spread and SP011 (dotted lines) denotes the model spread.

AMR Corporation
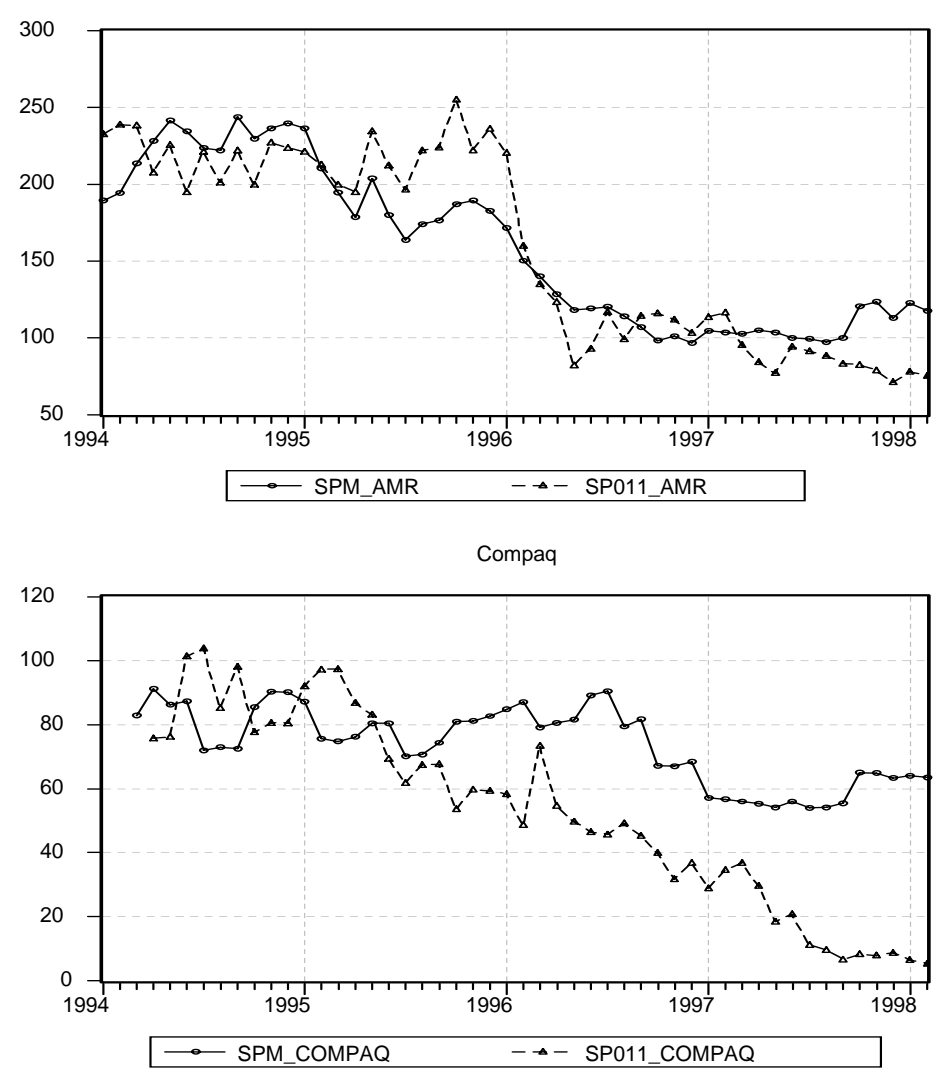

Bethlehem Steel

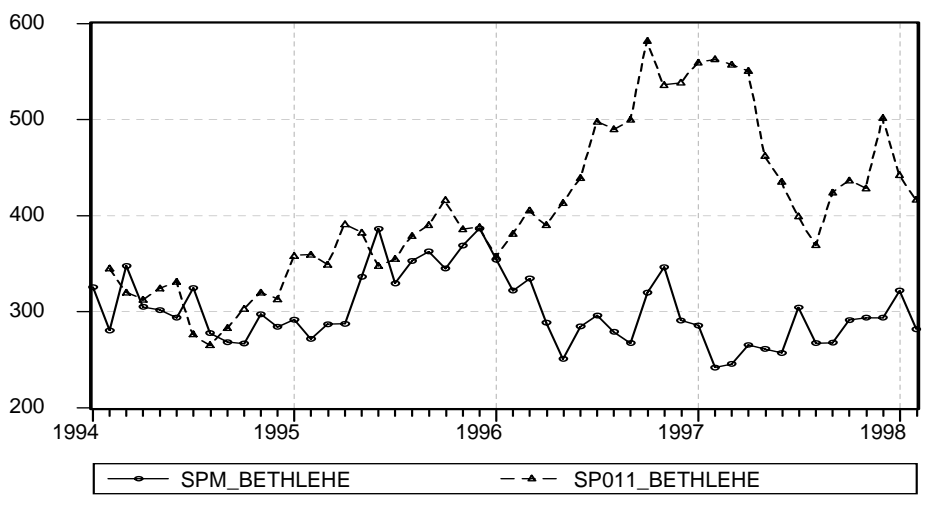

Federated Department Stores

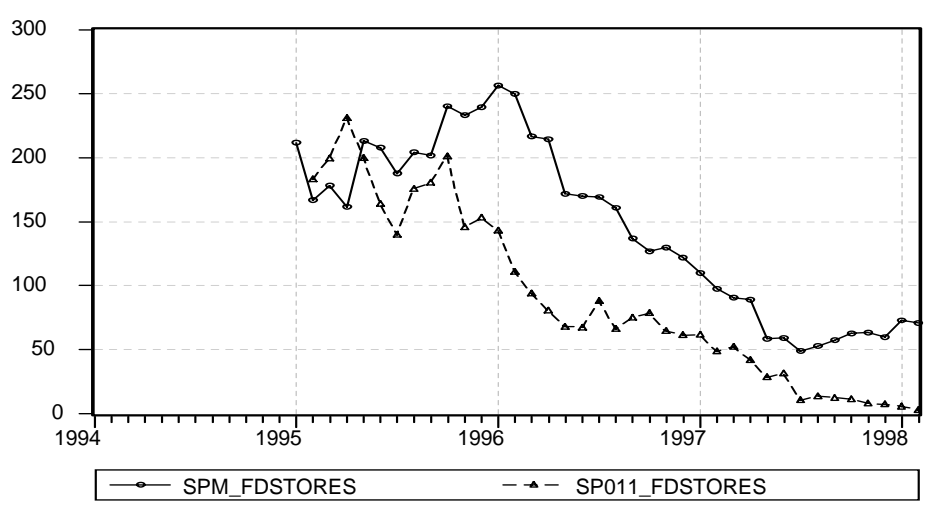




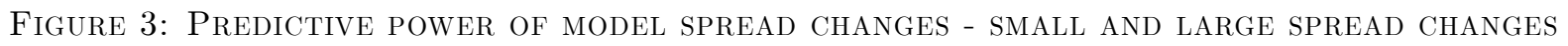

Plotter diagram of changes in market spreads (y-axis) vs. changes in model spreads (x-axis) from estimation with bond prices (however results are similar for changes without bond prices).
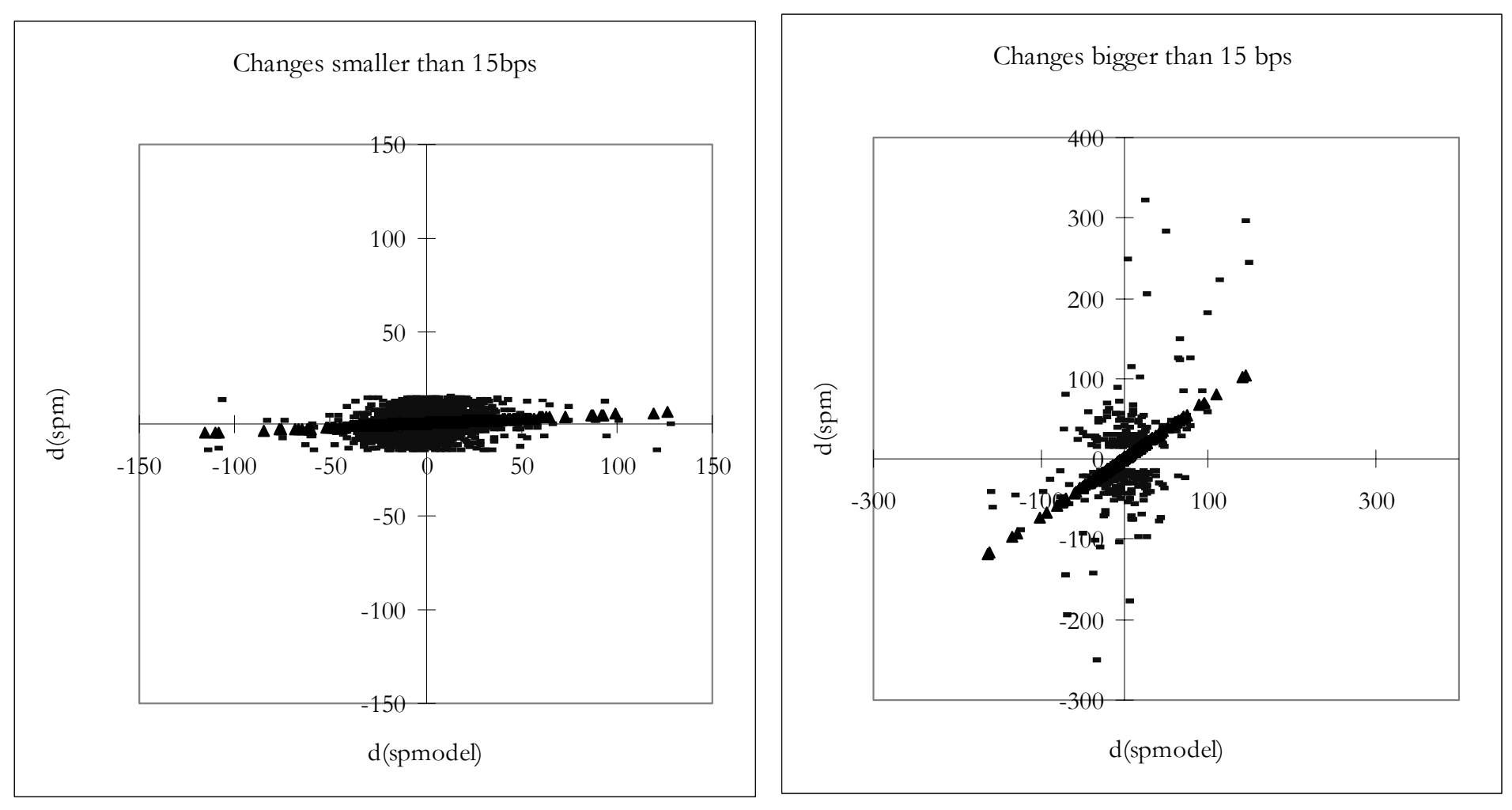
Figure 4: ERror Diversification

The standard deviation of the portfolio pricing errors is calculated as the average, across portfolios, standard deviation of relative pricing errors.

\section{Error diversification}

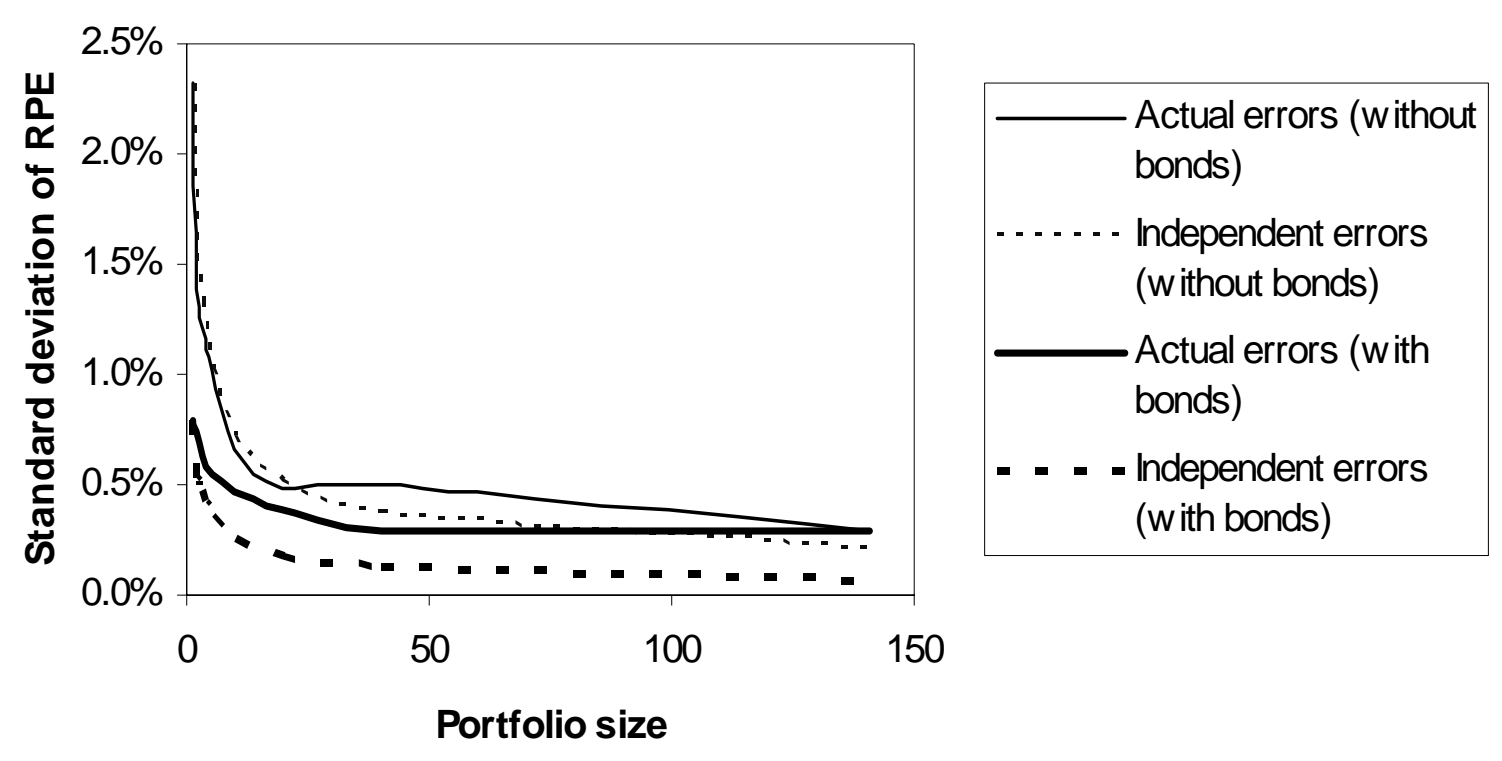


Figure 5: NON-DIVERsifiable PORTFOlio ERRORS

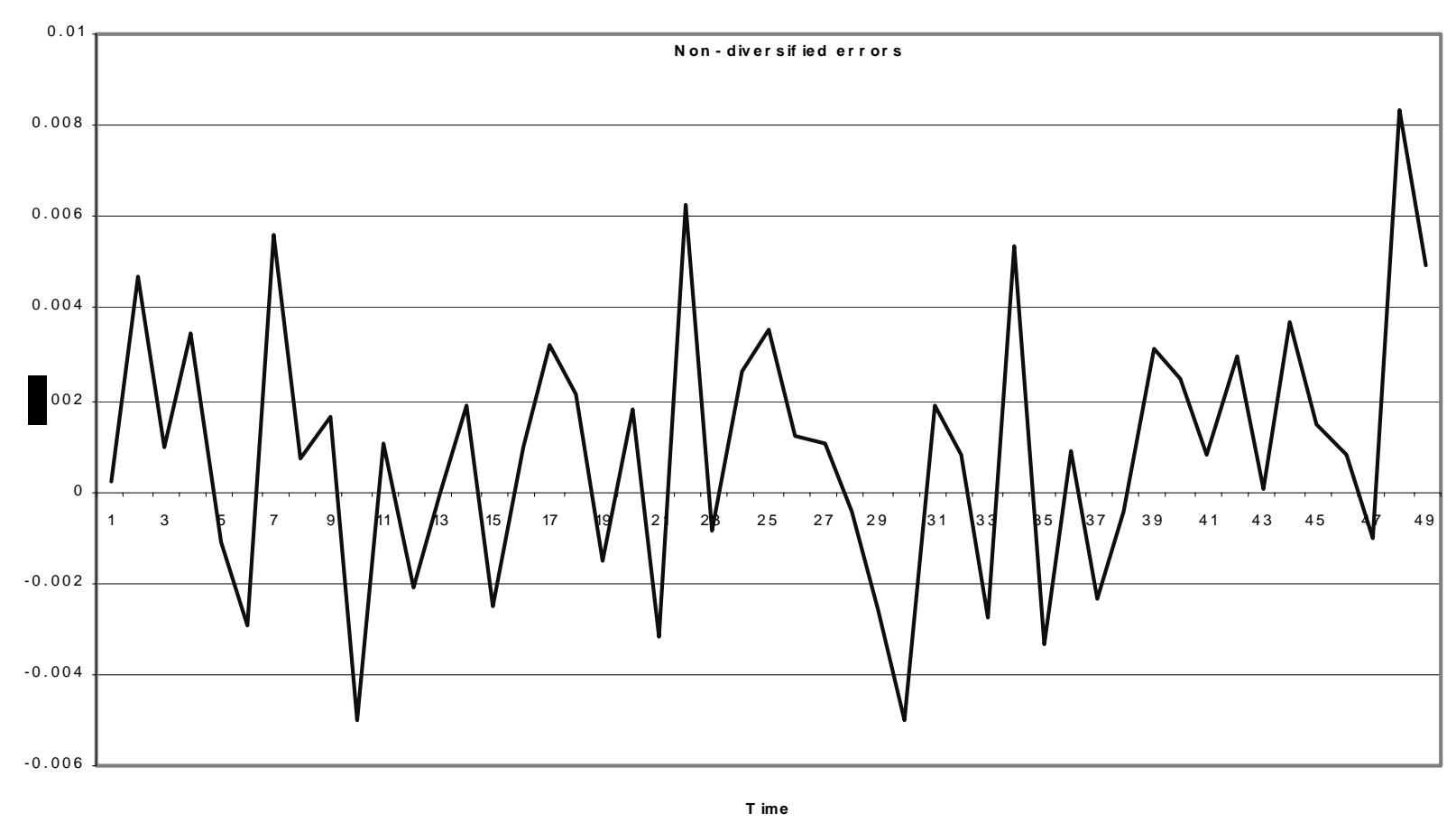

